\title{
Seismic Evaluation of Masonry Structures Strengthened with Reinforced Concrete Layers
}

\author{
Bahman Ghiassi ${ }^{1}$, Masoud Soltani2, ${ }^{2,}$, Abbas Ali Tasnimi ${ }^{3}$
}

\begin{abstract}
${ }^{1} \mathrm{PhD}$ student, Department of Civil and Environmental Engineering, Tarbiat Modares University, Tehran, Iran, Current address: ISISE, Department of Civil Engineering, University of Minho, Guimaraes, Portugal, 4800-058 (e-mail: bahmanghiassi@civil.uminho.pt)

${ }^{2}$ Associate Professor, Department of Civil and Environmental Engineering, Tarbiat Modares University, Tehran, Iran(e-mail: msoltani@modares.ac.ir)

${ }^{3}$ Professor, Department of Civil and Environmental Engineering, Tarbiat Modares University, Tehran, Iran (email: tasnimi@modares.ac.ir)

* Corresponding author: Fax: +98 21 82883381, Email: msoltani@modares.ac.ir
\end{abstract}

\begin{abstract}
Coating the walls with reinforced concrete layers is a conventional method of strengthening masonry structures in Iran. However, due to the lack of analytical and experimental information about the behavior of strengthened masonry wall with this method, the design of these walls is generally conducted based on empirical relations and decisions which may result in uneconomical or under-designed strengthening details. This paper aims at developing a rational method for design and seismic evaluation of unreinforced masonry walls strengthened with reinforced concrete (RC) layers. In the proposed method four failure modes are considered for these walls and the strength relations and acceptance criteria for each of them are provided in accordance with FEMA 356 and ASCE 41 relations for reinforced concrete and masonry walls. The accuracy of the proposed method in predicting the nonlinear behavior and governing failure modes of the strengthened walls is validated by comparing the results with available experimental and performed numerical results. Keywords: Seismic Evaluation, Design, Strengthening, Masonry Structures, RC layer.
\end{abstract}




\section{Introduction}

Most of the residential and historical buildings in Iran such as many other places in the world are made of unreinforced masonry. These structures consist of a large number of hospitals and schools, which their destruction due to the earthquakes has resulted in massive death of people. Recent earthquakes, such as Bam earthquake in Iran, have shown the severe vulnerability of this type of structures against seismic loads. This indicates the urgent need of strengthening these structures. During the last years a large amount of funds have been set up and extensive effort has started to improve the seismic behavior of masonry structures using different strengthening methods. These methods can be classified as: surface treatment (Ferrocement, FRP layer, shotcrete layer), grout and epoxy injection, external reinforcement, confining, and post-tensioning (ElGawady et al. 2004; Oliveira et al. 2011; Borri et al. 2011; Moon et al. 2007; Vintzileou 2008; Khan 1984; Abrams et al. 2007; Corradi et al. 2008).

Although a variety of techniques are being used for strengthening of masonry buildings and the advantages and disadvantages of them have been discussed in the technical literature, the information and technical guidelines which can help an engineer to judge the relative merits of these methods, are rare. An extensive effort has been devoted for proposing analytical methods to evaluate the seismic resistance and performance of strengthened masonry structures with different strengthening techniques in the recent years, see e.g. Abrams et al. 2007; Alok Madan et al. 2008.

Coating the walls with reinforced concrete layers is the most popular strengthening method for masonry structures in Iran. In this method a mesh of reinforcing bars is first placed on the face of the wall and then it is covered with a concrete layer. This layer may be placed on one or both sides of the wall. To assure the consistency of the deformations of the wall and concrete layers, the concrete and reinforcing bars should be appropriately anchored to the wall. Due to the lack of experimental and analytical information on this method, design and rehabilitation procedures are always based on empirical judgments or assuming the strengthened wall acts as a combination of unreinforced masonry and reinforced concrete layers. In these procedures the strength of the 
strengthened wall is calculated by the summation of the shear strength of each or some of the components of the strengthened wall (masonry wall, reinforcing bars, and concrete layers). These approaches have resulted in uneconomical and massive strengthening details and consequently expensive rehabilitation projects due to neglecting the following facts:

- Behavior of strengthened masonry wall is different from unreinforced masonry and consequently the cracking mechanism, the strength, and ductility of the wall change after strengthening.

- Using the available design relations of unreinforced masonry is not appropriate for computing the capacity of strengthened masonry walls.

- $\quad$ The strengthened masonry wall may fail under different failure modes in comparison with unreinforced masonry. Moreover, different strengthening details may result in different governing failure modes in the strengthened wall. Therefore, considering shear failure as the governing behavior in a strengthened wall, as it is assumed usually, may not be correct for all cases.

To overcome this problem, four failure modes are proposed for masonry walls strengthened with reinforced concrete layers in this paper based on the performed nonlinear analysis and the observed behavior in available experimental and analytical studies. The design relations, required parameters for linear and nonlinear seismic evaluation procedures, and bilinear curves for each failure mode are also given according to the observed behavior of these walls in accordance with FEMA 356 (2000) and ASCE 41 (2006) analysis procedures. The accuracy of the proposed relations and forcedeformation bilinear curves, and the ability of the proposed method to predict the governing behavior of strengthened walls are investigated by comparing the results with available experimental and analytical results. The results show that the proposed relations can predict the capacity, governing failure mode and nonlinear behavior of the strengthened walls with a reasonable accuracy. The main difference between the proposed method and experimental observations lies in predicting the ductility of the walls which should be modified and corrected by 
performing an extensive experimental program. Using the proposed design relations and acceptance criteria, the masonry structures strengthened with reinforced concrete layers can be simply designed and evaluated according to FEMA 356 (2000) and ASCE 41 (2006) linear and nonlinear analysis procedures.

\section{Strengthening method}

Strengthening masonry walls with reinforced concrete layers is a conventional method of strengthening in Iran. In this method a mesh of reinforcing bars is first placed in one or both sides of the wall and then it is covered with a thin concrete layer (Fig. 1). The concrete layer and reinforcing bars should be anchored to the wall to assure that the wall and reinforced concrete layers work together.

\section{Figure 1}

Due to the lack of analytical and experimental information on the seismic behavior of strengthened masonry walls, the evaluation and design procedures are usually conducted based on empirical approaches which may be un-conservative or uneconomical. These methods can be classified into three groups. In all of these methods, it is assumed that the failure in the strengthened wall occurs due to diagonal shear failure and the capacity of the wall is calculated according to this failure mode. Moreover, the capacity of the strengthened wall in these methods is usually obtained by the summation of the capacity of all or some components in the strengthened wall.

In the first method the wall capacity is obtained by the summation of shear capacity of the concrete layer, $V_{c}$, and shear reinforcements, $V_{s}$, (Eq. 1). In this method, it is assumed that the masonry contribution in shear capacity of the strengthened wall is small and it can be neglected. Also it is assumed that the concrete fails due to diagonal tension cracking and the shear capacity of the concrete layer is calculated according to this failure mode using conventional ACI-318 (2008) relation (Eq. 2). The steel contribution in this method is calculated according to Eq. 3.

$$
V_{R M}=V_{c}+V_{s}
$$


$V_{c}=0.17 \sqrt{f_{c}} t_{c} L \quad$ (in $\left.\mathrm{N} \mathrm{mm}\right)$

$V_{s}=0.5 f_{y} A_{v} \frac{h}{s}$

where $f_{c}$ is the concrete compressive strength, $t_{c}$ is the concrete thickness, $L$ is the wall length, $f_{y}$ is the yield strength of reinforcing bars, $A_{v}$ is the area of transverse reinforcement within a distance $s$, and $h$ is the wall height.

In the second method, it is assumed that the shear capacity of the strengthened wall can be obtained by the summation of the capacity of masonry wall, $V_{m}$, and the reinforcing bars (Eq. 4). In this method the contribution of masonry in shear capacity of the wall may be calculated in two different ways. One is to calculate the capacity of the masonry by assuming the shear sliding behavior and the other is to obtain it considering the governing behavior among four failure modes of masonry according to FEMA 356 (2000) or ASCE 41 (2006) (Rocking behavior, bed-joint sliding, diagonal tension, toe crushing). Neglecting the shear capacity of concrete in this method, being inconsistent with the engineering and mechanics principles, results in providing massive reinforcement details in retrofitting projects.

$V_{R M}=V_{m}+V_{s}$

In the third method, the capacity of the strengthened masonry wall is obtained by the summation of masonry, concrete, and reinforcing bars contribution (Eq. 5). In this method the concrete shear capacity is calculated according to conventional design relations (diagonal cracking, Eq. 3) and the masonry shear capacity is calculated according to four FEMA 356 (2000) failure modes. Following this approach it is possible that the governing behavior of the masonry is different with the concrete layer which is assumed to be diagonal cracking.

$V_{R M}=V_{m}+V_{c}+V_{s}$

The fact that the strengthened wall, when there is enough anchorage between concrete layer and masonry wall, acts as a new composite member is neglected in all these methods. The strengthened 
wall acting as a composite material will have the cracking behavior and failure modes corresponding to its properties which may be different from the unreinforced masonry. This important fact has been considered in design relations proposed in this study which are described in the next sections.

\section{A review of unreinforced masonry behavior}

Masonry is a composite material with orthotropic behavior which causes this material to have different failure modes. Four failure modes are usually considered for unreinforced masonry walls in the seismic evaluation procedures (e.g FEMA 356 (2000) and ASCE 41 (2006)) based on the observed actual behavior of these structures in earthquakes and experimental tests. The governing behavior of the masonry wall is assumed to be the failure mode in which the wall has the lowest capacity. These failure modes are classified as deformation-controlled (bed-joint sliding and rocking behavior) or force-controlled (diagonal tension cracking and toe compression failure) actions (Fig. 2). The deformation-controlled actions are the ones that after occurrence, a ductile behavior is expected in the member without considerable loss of strength. The force-controlled actions are oppositely the ones in which brittle behavior with sudden loss of strength is expected. Reaching the yield stress is not permitted for force-controlled members in earthquake resistant design procedures. In seismic evaluation guidelines, such as FEMA 356 (2000) and ASCE 41 (2006), the lower bound strengths and expected strengths of materials are used for obtaining the capacity of force-controlled and deformation-controlled actions, respectively.

Figure 2

The bed-joint sliding failure is considered as a deformation-controlled action in FEMA 356 (2000), while in the ASCE 41 (2006) it has been classified as force-controlled action (Discussions are underway with the ASCE 41 Standards Committee that will likely lead to a ballot proposal to redesignate bed-joint sliding as a deformation-controlled action in the next edition of ASCE 41).

However, as a ductile behavior has been observed in the single masonry walls with this failure mode in experimental tests, and as the seismic evaluation code of existing structures in Iran (Code 
$360,2007)$ assumes this failure mode as a deformation-controlled action, it has been considered deformation-controlled in this study. In this failure mode, slipping occurs in the bed-joints and may be in a straight or diagonal stepped pattern. The masonry shear strength against this failure mode can be calculated with the aim of friction theories and is proposed by FEMA 356 (2000) as follows: $V_{b j s}=v_{m e} A_{n}$

where $V_{b j s}$ is the masonry wall bed-joint sliding capacity, $A_{n}$ is the area of mortared section, and $v_{m e}$ is expected masonry shear strength. The term $v_{m e}$ has been substitute with $v_{m l}$, lower bound masonry shear strength in ASCE 41 (2006) as it is assumed a force-controlled action in this standard.

Rocking usually occurs when the wall shear strength is high, the wall is slender, and the compressive forces are low (FEMA 306, 1998). It is usually accompanied by a large deformation capacity limited by toe compression failure or wall instability. When rocking behavior continues in several cycles, it may be followed by the toe crushing. FEMA 356 (2000) and ASCE 41 (2006) propose Eq. 7 for computing the shear strength of unreinforced masonry for rocking and Eq. 8 for toe crushing.

$$
\begin{aligned}
& V_{r}=0.9 \alpha P_{E} \frac{L}{h_{e f f}} \\
& V_{t c}=\alpha P_{L} \frac{L}{h_{\text {eff }}}\left(1-\frac{f_{a}}{0.7 f^{\prime}{ }_{m}}\right)
\end{aligned}
$$

where $V_{r}$ is the wall rocking capacity, $\alpha$ is a factor equal to 0.5 for cantilever walls or 1.0 for fixed-fixed walls, $P_{E}$ is the expected axial compressive force due to gravity loads, $h_{\text {eff }}$ is the height to resultant force, $V_{t c}$ is the wall toe crushing capacity, $P_{L}$ is the lower bound axial compressive force due to gravity loads, $f_{a}$ is the axial compressive stress due to gravity loads, and ${f^{\prime}}_{m}$ is the lower bound compressive strength of masonry.

In diagonal tension behavior, a diagonal crack distributes over the wall. This behavior usually occurs in walls with strong mortar, weak units, and high compressive stresses (FEMA 306, 1998). 
In this behavior, small nonlinear deformations are expected. In most cases cracking occurs suddenly and the wall strength drops fast. The following equation is proposed in FEMA 356 (2000) to calculate the diagonal tension capacity of the wall:

$V_{d t}=A_{n} f_{d t} \frac{L}{h_{e f f}} \sqrt{\frac{f a}{f_{d t}}+1}$

where $V_{d t}$ is the wall diagonal tension capacity, and $f_{d t}$ is the lower bound masonry diagonal tension strength.

\section{Strengthened masonry behavior}

A masonry wall strengthened with reinforced concrete layer behaves as a new composite material when the RC layers are adequately anchored to the wall. In other words, the behavior of the masonry part is affected due to the presence of reinforced concrete layers. The strength and ductility of the strengthened wall are different from the unreinforced masonry, not only due to the excessive capacity of the concrete layer and reinforcing bars, but also because of the bond effect of reinforcing bars which affects the crack distribution in the masonry wall. In unreinforced masonry, the cracks are wide and concentrated in a small region of the wall, but in the strengthened masonry walls the bond forces due to reinforcing bars distribute the cracks over the wall. This results in different failure modes and capacity in the strengthened walls in comparison with unreinforced masonry.

Another important issue is that the different strengthening details may cause different nonlinear behavior and governing failure modes which are not considered in conventional design procedures. For example, the behavior of a masonry wall with rocking failure mode (ductile behavior) may be changed to diagonal tension (brittle behavior) after strengthening which results in a significant change in the ductility and strength of the wall. If this change in governing behavior is not considered in the design and evaluation procedures, as it is not in the conventional methods, it may result in an inaccurate retrofitting plan. 
For more clarification of the changes in the nonlinear behavior of masonry walls after strengthening, the nonlinear analytical program WCOMD (WCOMD-SJ User's Manual 2009) developed at University of Tokyo is used in this study. WCOMD is an analytical tool for twodimensional static and dynamic nonlinear analysis of reinforced concrete structures based on fixed smeared crack approach. This program is modified by Barimani et al. (2007) on the basis of the orthotropic material models developed by Lourenço et al. (1998) for nonlinear macro analysis of masonry structures. Also mortar joint model developed by Salehi (2010) has been modified and implemented in WCOMD for micro level modeling of masonry walls by Ghiassi (2009).

To check the reliability of the program in nonlinear analysis of masonry walls, two masonry walls tested at ETH Zurich (Ganz and Thurlimann 1984) are modeled and analyzed in WCOMD framework. The properties of the selected walls are shown in Table 1. The walls are tested under constant axial force and incremental shear displacements. The only difference between the walls $\mathrm{W} 1$ and W2 is the initial axial force applied to the walls which has resulted in different behavior and failure modes. The wall $\mathrm{W} 1$ is subjected to $0.61 \mathrm{~N} / \mathrm{mm}^{2}$ and $\mathrm{W} 2$ is subjected to $1.91 \mathrm{~N} / \mathrm{mm}^{2}$ axial forces. In the wall W1 extensive diagonal cracking was found accompanied by flexural cracks in the left flange with ductile behavior, but the wall W2 exhibited a brittle behavior due to compression failure. The walls are modeled based on a macro-modeling approach considering the masonry as a continuum media and using 8-node plane stress elements (Fig. 4).

Table 1

Figure 3

Figure 4

The analysis results are shown in Fig. 5 in comparison with the experimental behavior of the walls. The small difference between the analysis and experimental results is due to the fact that in the macro modeling approach a variety of parameters should be used and validated in each case. Also the assumptions that are usually made in macro modeling can be the reason for this difference. Using micro models results in a more accurate prediction of cracking and nonlinear behavior but 
the number of elements and the analysis time increases significantly (Lourenço 1996). Moreover, suitable material constitutive models for each component should be adopted for obtaining reasonable results in this modeling approach. For investigating different effects of chosen methods in the analysis results, the wall $\mathrm{W} 1$ is modeled following both macro and micro-modeling approaches. It can be seen in Fig. 6 that the nonlinear behavior obtained by micro modeling follows the experimental result with a better accuracy in comparison to macro modeling approach. However, as the results obtained from the macro-modeling approach (Fig. 5) have a reasonable accuracy, this approach is followed for modeling the strengthened walls.

Figure 5

Figure 6

In order to investigate the changes in the behavior of the walls after strengthening, the walls W1 and W2 are modeled with different strengthening details, RET1 and RET2 (Table 2). The strengthened masonry is modeled by adding a reinforced concrete layer to the finite element model of the wall using overlap elements. The load-displacement curves of strengthened walls are shown in Fig. 7. The changes in the nonlinear behavior and failure modes of the walls due to different strengthening details are obvious in this figure. The wall W1 has a flexural behavior together with diagonal cracks. After strengthening with the first detail, RET1, an increase in the capacity of the wall is observed without any change in the failure mode and ductility, while the second strengthening detail resulted in a brittle behavior (diagonal tension behavior) in the strengthened wall.

In wall W2, the second detail of strengthening, RET2, with twice as much vertical reinforcing steel than horizontal reinforcing steel resulted in an increase in the capacity of the wall with the same failure mode (toe compression) and almost the same ductility as the unretrofitted wall, while the first detail, RET1, resulted in more capacity and ductility in the wall. These comparisons clearly show the importance of choosing appropriate strengthening details for the walls and their significant influence on the nonlinear behavior of the strengthened walls. 
Table 2

Figure 7

For more investigation, two unreinforced masonry walls with rocking and shear sliding behavior are strengthened and modeled in WCOMD program. To assure the occurrence of appropriate failure modes in unreinforced walls, joint elements are used in selected places. For example in the wall with bed-joint sliding, the joints are placed in the middle height of the wall to be sure that the sliding behavior occurs in that region (Fig. 8). Wall thickness is $220 \mathrm{~mm}$ and the axial load equal to $40 \mathrm{KN}$ is applied at the top of the wall. Firstly, the unreinforced masonry wall is analyzed and the nonlinear behavior and crack propagation are obtained. After that, the walls are strengthened, analyzed, and the results are compared with the unreinforced walls. The strengthening details and obtained governing failure mode of the walls are shown in Table 3. It can be seen that the strengthening details in $\mathrm{B} 3, \mathrm{~B} 4, \mathrm{R} 2$ and $\mathrm{R} 3$ walls resulted in changing the failure mode to a brittle behavior followed by diagonal cracks. The diagonal cracks formed in wall B3 in masonry and concrete layers are shown in Fig. 9 separately as an example.

Figure 8

Table 3

Figure 9

The shear-displacement curves of the walls are also shown in Figs. 10, 11. The results show that besides the increase in capacity of the walls after strengthening, the ductility may be increased or decreased according to the strengthening detail. In other words, the strengthened wall may have a brittle or ductile behavior depending on the strengthening detail.

Figure 10

Figure 11

\section{Proposed failure modes for strengthened wall}

Seismic evaluation of existing structures is usually conducted following linear or nonlinear analysis procedures by dividing the members failure modes to force-controlled and deformation-controlled 
actions. The members should have enough capacity against the applied loads without yielding and plastic deformations in force-controlled actions. Therefore, force demands in force-controlled actions should be less than the member capacity. In deformation-controlled actions, the member is expected to show suitable ductility without considerable strength reduction. Moreover the plastic deformations are usually divided by some limits defining the performance levels of the member (such as immediate occupancy or life safety level). Considering the observed nonlinear behavior of masonry walls, these limitations are given in seismic evaluation guidelines (such as FEMA 356 (2000) and ASCE 41 (2006)) and can be obtained based on the nonlinear behavior, stability, and boundary conditions of the wall. In nonlinear analysis procedures, the simplified force-deformation curves (Fig. 12) and acceptance criteria for each performance level are defined. These curves can be used for defining nonlinear hinges in nonlinear analysis procedures. The member is assumed acceptable when its nonlinear deformations are less than the acceptance criteria of suitable performance level. For linear analysis procedures a capacity modification factor, $m$-factor, is defined for each deformation-controlled action which is expected to account the nonlinear behavior of the member. In this analysis procedure the member is assumed accepted when the production of the capacity of the wall to the appropriate $m$ factor is larger than the applied forces. For a more indepth discussion of these concepts FEMA 356 (2000) and ASCE 41 (2006) can be referred.

Figure 12

In this section, the proposed failure modes and strength relations in each failure mode for strengthened masonry walls with reinforced concrete layers are presented. Also the proposed forcedeformation parameters and acceptance criteria for nonlinear analysis and the $m$-factors for linear analysis procedures (according to FEMA 356 (2000) and ASCE 41 (2006) analysis methods) are presented. As the behavior of the strengthened masonry wall can be similar to the reinforced masonry and reinforced concrete walls, the probable failure modes and strength relations are proposed considering the available relations in FEMA 356 (2000) and ASCE 41 (2006) for these walls. Based on the available experimental and conducted analytical studies, four failure modes are 
proposed for strengthened masonry walls: flexural behavior (rocking), shear failure (diagonal tension), shear sliding failure, and compressive failure.

\subsection{Flexural behavior}

\subsubsection{Strength}

The shear-displacement curve of a RC wall under flexural actions (Fig. 13) has three primary points representing the concrete cracking, reinforcing bars yielding, and concrete compressive crushing. In the RC shear walls, usually the concrete cracking occurs first, followed by reinforcement yielding which govern the capacity of the wall, and the concrete crushing which limits the wall ductility. In the walls with low reinforcement ratio, the wall may show a sudden decrease in strength after the cracking point which is due to having a lower reinforcement yielding capacity than the cracking capacity. The flexural mechanism in strengthened masonry walls is similar to RC shear walls.

\section{Figure 13}

The flexural strength of a strengthened masonry wall can be calculated by means of simple flexure theory, based on the assumption that the plane sections remain plane after bending. Using a rectangular compression stress block with a stress level of $0.85 f^{\prime}{ }_{r m}$ and with a depth of "a" and writing the equilibrium equations, the flexural strength can be computed as follows (Fig. 14):

$$
\begin{aligned}
& M_{n}=0.5 A_{s} f_{y} l_{w}\left(1+\frac{N_{r}}{A_{s} f_{y}}\right)\left(1-\frac{c}{l_{w}}\right)+A_{s b} f_{y} d \\
& \frac{c}{l_{w}}=\frac{\omega+\alpha}{2 \omega+0.722} \\
& \omega=\frac{A_{s}}{l_{w} t_{w}} \frac{f_{y}}{f^{\prime}{ }_{r m}} \\
& \alpha=\frac{N_{u}}{l_{w} h f^{\prime}{ }_{r m}}
\end{aligned}
$$

where $l_{w}$ is the wall effective length equal to 0.8 of the wall actual length, $N_{r}$ is the wall axial force, $A_{S}$ is the area of vertical reinforcing bars, $A_{S b}$ is the total area of reinforcing bars in boundary zone, $t_{w}$ is the wall thickness, and $f^{\prime}{ }_{r m}$ is the strengthened masonry compressive 
strength which can be obtained from compressive test results. Since experimental results on compressive behavior of strengthened masonry walls are not available yet, the equivalent compressive strength can be calculated as (Fig. 15):

$$
f^{\prime}{ }_{r m}=\varepsilon_{u} E_{r m \mathrm{sec}}
$$

where $\varepsilon_{u}$ is the peak strain and can be used equal to 0.003 , and $E_{r m \mathrm{sec}}$ is the secant modulus of elasticity that is equal to half of the initial modulus of elasticity of the strengthened masonry. The initial modulus of elasticity of the strengthened masonry can be computed as (Ghiassi 2009):

$$
E_{r m}=\left(-0.068 \frac{t_{m}}{t_{c}}+1.068\right)\left(0.243 \frac{E_{m}}{E_{c}}+0.45 \frac{E_{b}}{E_{c}}+0.335\right) E_{c}
$$

where $t_{m}$ is the masonry wall thickness, $t_{c}$ is the concrete layer thickness, $E_{m}$ is the mortar modulus of elasticity, $E_{b}$ is the brick modulus of elasticity and $E_{c}$ is the concrete modulus of elasticity.

Figure 14

Figure 15

\subsubsection{Deformation}

Flexural failure is a ductile behavior in which a large amount of energy can be dissipated through reinforcement yielding. The ductility of the wall under this behavior is usually limited by concrete compressive crushing or shear failure of the wall. The displacement capacity of a flexural strengthened wall can be determined with reasonable accuracy by idealizing it as a cantilever beam and calculating the flexural and shear deformations. As the behavior of strengthened masonry walls is similar to reinforced concrete and masonry walls, it can be idealized as having a plastic hinge zone at the base and the ultimate displacement can be calculated using the methods presented in Lourenço 1996. FEMA 356 (2000) and ASCE 41 (2006) propose displacement acceptance criteria for reinforced masonry walls, which can be used for strengthened masonry walls due to the resemblance of nonlinear behavior and basics for selecting the performance levels. Therefore, due to the lack of experimental data on nonlinear behavior of strengthened masonry walls, the use of 
acceptance criteria, force-displacement parameters (for nonlinear analysis) and $m$-factors (for static analysis) of reinforced masonry walls with some modifications is proposed (Table 4). However these values should be verified by performing an extensive experimental program.

\subsection{Shear behavior (diagonal tension)}

\subsubsection{Strength}

Diagonal tension cracking behavior in unreinforced masonry walls is accompanied by wide diagonal cracks concentrated in a small region of the wall. Depending on the wall properties, the diagonal cracks may occur in a straight path through the joints and units or with a stepped path through the head and bed joints (Fig. 16). When the cracks form in a stepped pattern, the masonry shows little ductility and strength reduction (Lourenço 1996). The strength of the wall against diagonal stepped cracking can be obtained using bed-joint sliding relations. In straight crack pattern, the response of unreinforced masonry wall to its failure mode is considered brittle and is categorized as a force-controlled behavior in FEMA 356 (2000) and ASCE 41 (2006) as described before.

\section{Figure 16}

In reinforced masonry walls the cracks are smaller and distributed over the entire surface of the wall due to the bond stress of reinforcing bars (Fig. 17). In these walls, the reinforcing bars affect the surrounding material and prevent separation of the wall's cracked parts and therefore the cracks propagate over the entire surface of the element resulting in an increase in strength and ductility of the wall. FEMA 356 (2000) and ASCE 41 (2006) categorize this failure mode in reinforced masonry as a ductile behavior with small ductility and propose the following relation for calculating the strength of the wall under this failure mode:

$$
\begin{aligned}
& V_{C L}=V_{m}+V_{s}+V_{p} \\
& V_{C L} \leq 6 \sqrt{f^{\prime}{ }_{m}} A_{n} \text { for } \frac{M}{V d_{v}} \leq 0.25 \quad(\text { in } \mathrm{N} \mathrm{mm})
\end{aligned}
$$




$$
\left.V_{C L} \leq 4 \sqrt{f^{\prime}{ }_{m}} A_{n} \text { for } \frac{M}{V d_{v}} \geq 1.0 \quad \text { (in } \mathrm{N} \mathrm{mm}\right)
$$

where $V_{C L}$ is the lower bound shear strength of the reinforced masonry wall, $M$ is the applied moment on the masonry section, $V$ is the shear force applied to the masonry section, and $d_{v}$ is the wall length in direction of the applied shear. In Eq. 16, $V_{s}$ can be obtained using Eq. 3, and $V_{m}$ and $V_{p}$ are masonry and axial force contribution in shear strength of the wall respectively and can be obtained as follows:

$$
\begin{aligned}
& V_{m}=0.083\left(4-1.75 \frac{M}{V . d_{v}}\right) A_{n} \sqrt{f^{\prime}{ }_{m}} \quad(\text { in } \mathrm{N} \mathrm{mm}) \\
& V_{p}=0.25 P_{u}
\end{aligned}
$$

where, $A_{n}$ is the area of net mortared/grout section and $P_{u}$ is the lower bound compressive force due to gravity forces.

\section{Figure 17}

Due to the different nonlinear behavior and cracking mechanisms in reinforced and unreinforced masonry, different shear failure and mechanisms occur in them, which is obvious in the design relations in Eqs. 12,16 . This difference is because of the bond effect of reinforcing bars in reinforced masonry that prevent the formation of wide cracks concentrated in a small region. This results in activation of the aggregate interlock between two faces of the crack and consequently increasing the capacity of the masonry. It should be noted that in Eq. 16, it is assumed that the entire thickness of the wall is under the bond effect of reinforcing bars which can be obtained by the placement of a minimum reinforcement ratio at the center of the wall (Fig. 18, top). In the cases that the reinforcing bars are not enough to affect the whole thickness of the wall, the bond zone will be smaller than the wall thickness, and the parts of the wall which are out of the bond zone of reinforcing bars bond, act as unreinforced masonry (Fig. 18, bottom).

Figure 18 
The shear behavior of strengthened masonry wall is similar to reinforced masonry. The difference is that in strengthened masonry wall the reinforcements are placed in one or both sides of the wall and not in the center. In these walls, depending on the ratio and type of reinforcing the whole thickness of the wall may or may not be under the bond effect of reinforcing bars. Considering this fact, the following relation is proposed for calculating the shear strength of the strengthened masonry walls based on the existing relations for reinforced masonry:

$$
\begin{aligned}
& V_{s r m}=V_{m}+V_{c}+V_{s}+V_{p} \\
& \left.V_{m}=\alpha \times 0.083\left(4-1.75 \frac{M}{V \cdot d_{v}}\right) A_{g} \sqrt{f^{\prime}{ }_{r m}} \quad \text { (in } \mathrm{N} \mathrm{mm}\right) \\
& V_{c}=0.53 \sqrt{f^{\prime}{ }_{c}} t_{c} d \\
& V_{s}=0.5 f_{y} A_{v} \frac{d_{v}}{s} \\
& V_{p}=0.25 P_{u}
\end{aligned}
$$

where $d_{v}$ is the wall effective length equal to 0.8 total length of the wall and $\alpha$ is the bond effect parameter. Many studies have been performed for investigating bond effect of reinforcing bars and bond zone calculation in reinforced concrete elements. The bond zone is defined as the area around a reinforcing bar that is under its bond effect. Several relations are proposed by different authors for calculating the bond zone. CEB-FIB model code (1990) and Collins and Mitchell (1991) proposed that the bond zone around a reinforcing bar in reinforced concrete elements is equal to a square with the lengths of 15 times the bar diameter (Fig. 19). Considering the bond zone of reinforcing bars, the parameter $\alpha$ is proposed as follows to compute the effective area of strengthened masonry:

$$
\begin{aligned}
& \alpha=\phi_{1} \times \phi_{2} \\
& \phi_{1}=\frac{15 n \times d}{L} \leq 1 \\
& \phi_{2}=\frac{7.5 \times d}{t_{m}} \leq 1
\end{aligned}
$$


where $d$ is the reinforcing bars diameter, $n$ is the number of reinforcing bars. The parameter $\alpha$ can be assumed equal to 1 in cases in which the both sides of the wall are strengthened.

Figure 19

\subsubsection{Deformation}

The diagonal crack behavior is a brittle failure mode in unreinforced masonry walls, but the reinforced masonry and concrete walls show little ductility when this failure mode occurs. Because of the similarity of this failure mechanism between strengthened masonry and reinforced masonry walls, it is proposed to use FEMA 356 (2000) or ASCE 41 (2006) acceptance criteria, forcedisplacement parameters (for nonlinear analysis) and $m$-factors (for static analysis) of reinforced masonry walls (Table 4) for this failure mode.

\subsection{Shear sliding behavior}

\subsubsection{Strength}

This behavior can be described with the aim of the friction theories. The strengthened walls with low vertical reinforcement ratio and light axial loads may be vulnerable to this behavior. Also in large curvature ductility in flexural behavior, the shear sliding strength degrades and shear failure after yielding of reinforcing bars is possible to happen. FEMA 306 (1998) proposes Eq. 30 for computing the reinforced masonry strength in shear sliding failure mode.

$Q_{C E}=V_{s e}=\mu P_{u}+\mu A_{v f} f_{y e}$

where $P_{u}$ is the wall axial load, $A_{v f}$ is the area of reinforcing bars perpendicular to the sliding plane, $f_{y e}$ is the expected yield strength of reinforcing bars, and $\mu$ is the coefficient of friction that for mortar in brick masonry is expected to be equal to 0.7 . This equation is modified for strengthened masonry as follows:

$Q_{C E}=V_{s e}=\mu_{1} P_{u}+\mu_{2} A_{v f} f_{y e}$

where $\mu_{1}$ is the coefficient of friction of brick masonry and $\mu_{2}$ is the coefficient of friction of concrete that can be taken equal to 0.9 . 


\subsubsection{Deformation}

The deformation capacity of the strengthened wall under shear sliding behavior may be limited with the fracture of reinforcing bars, crushing of the base, or degradation of the shear strength (FEMA 306, 1998). Since the available experimental results are rare for this behavior and because of the similarity in performance criteria in this behavior with bed-joint sliding in unreinforced masonry, the same values of $m$-factors and nonlinear parameters could be used in evaluation procedures (Table 4).

\subsection{Compressive behavior}

\subsubsection{Strength}

FEMA 356 (2000) and ASCE 41 (2006) propose Eq. 32 for vertical compressive strength of reinforced masonry walls:

$Q_{C L}=P_{C L}=0.8\left[0.85 f^{\prime}{ }_{m}\left(A_{n}-A_{s}\right)+A_{s} f_{y}\right]$

As this behavior in strengthened masonry walls is similar to reinforced masonry, the same equation can be used by using the strengthened masonry compressive strength (Eq. 14) instead of masonry compressive strength as follows:

$Q_{C L}=P_{C L}=0.8\left[0.85 f^{\prime}{ }_{r m}\left(A_{n}-A_{s}\right)+A_{s} f_{y}\right]$

\subsubsection{Deformation}

This behavior is proposed to be assumed as a force-controlled action and nonlinear deformations should be avoided to prevent strength and stability failure in this mode.

\section{Table 4}

\section{Verification of the proposed method}

In this section, the validity of the proposed method is investigated by comparing the results with available experimental data. Since available experimental results are rare, an analytical study is also performed for investigating the accuracy of the proposed relations.

\subsection{Experimental Verification}


Yaghoubifar (2008) investigated the effectiveness of this strengthening technique applied on one or both sides of the wall by performing static-cyclic testes. He used two unreinforced masonry walls, NSBW1 and NSBW2, with different failure modes as the basic specimens (Fig. 20). Two strengthening details on each of the basic specimens were used to study the changes in behavior after strengthening. The governing behavior of unreinforced walls was rocking in NSBW1 and bedjoint sliding in NSBW2. The material properties and reinforcement details of the strengthened specimens are shown in Table 5. The SSBW1 and SSBW2 were strengthened on one side and DSBW1 and DSBW2 were strengthened on both sides of the wall. The capacity and failure mode of the strengthened walls predicted with the proposed evaluation procedure are compared with the tests results in Table 6. The proposed bilinear curves are also shown in Fig. 21 in comparison to the pushover curves of the tests results. It can be seen that the proposed bilinear curves are in good agreement with experimental results in this case.

Figure 20

Table 5

Table 6

Figure 21

The tests performed on strengthened masonry walls by Elgawady et al. (2006), specimen S21SHOT-ST, and Abrams et al. (2007), Specimen 4F, are also selected for more investigation of the accuracy of the proposed relations. Elgawady et al. (2006) performed static cyclic tests on masonry walls strengthened with shotcrete layer on both and single side of the wall and showed that strengthening the walls on both sides with the same reinforcement ratio will result in a more ductile behavior in comparison to strengthening on one side. The strengthening details and material properties of the selected walls are shown in Table 7. The experimental results together with the proposed bilinear curves are shown in Fig. 22 for both walls. It can be seen in this figure that the strength and governing failure mode in the walls are predicted accurately. 
Figure 22

\subsection{Numerical Verification}

In this section some masonry walls are strengthened with different details and analyzed using WCOMD framework. The strength and nonlinear behavior of the walls are also predicted using the proposed relations and the bilinear curves are compared with the numerical results.

Firstly, for more clarification about the changes in the behavior and failure modes of the walls after strengthening, the nonlinear behavior of the W1 and W2 walls tested in ETH Zurich (Ganz and Thurlimann 1984) is compared with the bilinear curves and the failure modes obtained using the FEMA 356 (2000) and ASCE 41 (2006) procedures (Fig. 23). It can be seen that the nonlinear behavior and failure mode of the wall W1 is predicted accurately, while in wall W2 even though the failure mode is predicted correctly, the nonlinear behavior is not accurately predicted. This difference shows the variety of parameters affecting the nonlinear behavior of masonry walls and the complexity of predicting their behavior following simplified procedures.

Figure 23

These walls are modeled in WCOMD with different strengthening details as shown in Table 8 . The nonlinear behavior and strength of the walls are also predicted by using the proposed relations in this paper. It is found that the predicted strength and failure mode of the strengthened walls are in line with the analysis results as it is shown in Table 9. The changes in nonlinear behavior of the walls after strengthening for W1-1 and W2-1 specimens are shown in Fig. 24. The wall W1-1 shows an increase in the capacity and a small increase in the ductility comparing to the bare wall, while in the wall W2-1 the failure mode has changed from a brittle to a ductile behavior. It can be seen that the proposed bilinear curves can predict the nonlinear behavior of strengthened walls with an acceptable degree of precision.

Table 8

Table 9

Figure 24 


\section{Conclusions}

The conventional methods of design and evaluation of strengthened masonry walls with reinforced concrete layers have resulted in massive retrofitting details because of considering inaccurate failure modes and using improper relations. To account for this problem, a seismic evaluation method is proposed in this study according to available experimental data and conducted numerical analysis. In the proposed method, four failure modes are considered for strengthened masonry walls. The design relations, linear, and nonlinear static analysis parameters according to FEMA reports for each failure mode are also given.

The accuracy of the proposed relations and bilinear curves is verified by comparing the results with available experimental and performed analytical results. It is shown that the proposed method is able to accurately predict the failure mode and capacity of the strengthened walls. It should be noted that the need for conducting more extensive experimental research is crucial for better understanding the nonlinear behavior of strengthened masonry walls with reinforced concrete layer and improvement of the proposed method precision especially in predicting the nonlinear deformation capacities.

\section{Acknowledgements}

The writers greatly acknowledge Professor Koichi Maekawa at Civil Engineering Department of The University of Tokyo for supporting this study by providing the WCOMD software.

\section{References}

Abrams, D., Smith, T., Lynch, J., Franklin, S. (2007). "Effectiveness of Rehabilitation on Seismic Behavior of Masonry Piers.” Journal of Structural Engineering ASCE, 133(1), 32-43.

ACI Committee 318 (2008). "Building code requirements for reinforced concrete (ACI 318-08) and Commentary (318R-08)". American Concrete Institute, Farmington Hills, Mich.

Alok Madan, A., Reinhorn, A. M., Mander, J. B. (2008). "Fiber-Element Model of Posttensioned Hollow Block Masonry Shear Walls under Reversed Cyclic Lateral Loading." Journal of Structural Engineering ASCE, 134(7), 1101-1114. 
ASCE 41 (2006). "Rehabilitation of Existing Buildings. ”, ASCE/SEI 41-06.

Barimani, S., Soltani, M., Tasnimi, A. A. (2007) "Developement of the constitutive models and analysis of infilled RC frames with fixed smeard crack method." $7^{\text {th }}$ Internationa Conference of Civil Engineering, Tehran.

Borri, A., Castori, G., Corradi, M. (2011) "Shear behavior of masonry panels strengthened by high strength steel cords.” Construction and Building Materials, 25(2), 494-503.

CEB-FIB (1990), "Model code for concrete structure". Comite Euro-International Du Beton, Paris.

Code 360 (2007). "Instruction for seismic rehabilitation of existing buildings." Management and Planning Organization, Tehran.

Collins, M.P., Mitchell, D. (1991) “Prestressed concrete structures.” PRENTICE HALL, New Jersey.

Corradi, M., Tedeschi, C., Binda, L., Borri, A. (2008). "Experimental evaluation of shear and compression strength of masonry wall before and after reinforcement: Deep repointing." Construction and Building Materials, 22(4), 463-72.

ElGawady, M., Lestuzzi, P., Badoux, M. (2004). “A review of conventional seismic retrofitting techniques for URM.” 13ht international brick and block masonry conference. Amesterdam.

ElGawady, M., Lestuzzi, P., Badoux, M. (2006). "Retrofitting of masonry walls using shotcrete." NZSEE Conference, New Zealand.

FEMA306. (1998). "Evaluation of Earthquake Damaged Concrete and Masonry Wall Buildings.” ATC, Washington.

FEMA 356 (2000). "Prestandard and Commentary for the Seismic Rehabilitation of Buildings." ATC, Washington.

Ganz, H. R., Thurlimann, B. (1984), “Tests on masonry walls under normal and shear loading.” REPORT No. 7502, Inst of Struct. Engrg., ETH Zurich. Zurich, Switzerland (In German). 
Ghiassi, B. (2009). "Homogenization and development of constitutive models for seismic evaluation of brick masonry structures retrofitted with reinforced concrete layer." M.Sc. Thesis. In Department of Civil Engineering, Tarbiat Modares University. Tehran, Iran.

Kahn, L. (1984). "Shotcrete retrofit for unreinforced brick masonry." Proceedings of the 8th World Conference on Earthquake Engineering, USA.

Lourenço, P. B. (1996). “Computational strategies for masonry structures.” PHD Thesis, Delft University of Technology, Delft, The Netherlands.

Lourenço, P. B., Rots, G., Blaauwendraad, J. (1998). “Continum model for masonry: parameter estimation and validation. Journal of Structural Engineering, 124(6), 642-52.

Moon, F. L., Yi, T., Leon, R. T., Kahn, L. F. (2007). “Testing of a Full-Scale Unreinforced Masonry Building Following Seismic Strengthening." Journal of Structural Engineering, 133(9), 1215-1226.

Oliveira, D. V., Basilio, I., Lourenço, P. B. (2011). "Experimental Bond Behavior of FRP Sheets Glued on Brick Masonry.” Journal of composites for construction, ASCE, 15(1), 32-41.

Paulay, T., Priestley, M. J. N. (1992). Seismic design of reinforced concrete and masonry buildings. New York, John Wiley \& Sons.

Salehi, I., Soltani, M., Tasnimi, A. A. (2010). "Nonlinear behaviour of masonry joints in shear". The Modares Journal of Civil Engineering Journal, 36, 79-98 (In Persian).

Vintzileou, E. (2008), "Effect of Timber Ties on the Behavior of Historic Masonry." Journal of Structural Engineering, 134(6), 961-972.

WCOMD-SJ User's Manual (2009). Concrete Engineering Laboratory, Department of Civil Engineering, The University of Tokyo.

Yaghoubifar, A. (2008). "Experimental and analytical investigation on the behavior of strengthened brick walls by steel bars and concrete.” M.Sc. Thesis. In Department of Civil Engineering, Tarbiat Modares University. Tehran, Iran. 


\section{List of Tables}

Table 1: W1 and W2 material properties.

Table 2: W1 and W2 strengthening details.

Table 3: Strengthening details adopted for base walls.

Table 4: Nonlinear and linear static procedure parameters for strengthened walls.

Table 5: Yaghoubifar (2008) strengthened Specimens.

Table 6: Capacity prediction of Yaghoubifar (2008) strengthened specimens.

Table 7: Strengthening details in S2-1SHOT-ST wall.

Table 8: Strengthening details adopted for wall W1.

Table 9: Comparison of analysis and proposed relations.

\section{List of Figures}

Fig. 1: Typical detail of masonry wall strengthening with reinforced concrete layer.

Fig. 2: Failure modes in unreinforced masonry walls.

Fig. 3: Geometry of the ETH Zurich walls.

Fig. 4: The generated mesh for macro modeling of the ETH Zurich walls.

Fig. 5: Analysis results for walls W1 and W2.

Fig. 6: Micro modeling results for wall W1.

Fig. 7: W1 and W2 strengthened walls behavior.

Fig. 8: Finite element model of masonry wall with bed-joint sliding behavior.

Fig. 9: Crack distribution in wall B3.

Fig. 10: Shear displacement curve of the strengthened walls with initial bed-joint-sliding behavior.

Fig. 11: Shear displacement curve of the strengthened walls with initial rocking behavior.

Fig. 12: General force-deformation curve.

Fig. 13: Moment curvature behavior of a strengthened masonry wall.

Fig. 14: The wall section and assumed stress distribution.

Fig. 15: Equivalent compressive strength.

Fig. 16: Crack distribution in unreinforced masonry.

Fig. 17: Crack distribution in: reinforced masonry.

Fig. 18: Bond zone in reinforced masonry.

Fig. 19: Definition of RC zone.

Fig. 20: Basic unreinforced masonry specimens tested by Yaghoubifar (2008).

Fig. 21: SSBW1 and DSBW2 bilinear curves.

Fig. 22: Comparison of experimental result with proposed bilinear curves.

Fig. 23: Behavior of wall W1 and W2.

Fig. 24: Bilinear curves of the strengthened walls. 


\section{Tables}

Table 1: W1 and W2 material properties.

\begin{tabular}{|c|c|c|c|c|c|c|c|c|}
\hline $\begin{array}{c}E_{x} \\
(\mathrm{MPa})\end{array}$ & $\begin{array}{c}E_{y} \\
(\mathrm{MPa})\end{array}$ & $\begin{array}{c}f_{t x} \\
(\mathrm{MPa})\end{array}$ & $\begin{array}{c}f_{t y} \\
(\mathrm{MPa})\end{array}$ & $\begin{array}{c}f_{m x} \\
(\mathrm{MPa})\end{array}$ & $\begin{array}{c}f_{m y} \\
(\mathrm{MPa})\end{array}$ & $\alpha$ & $\beta$ & $\gamma$ \\
\hline 2460 & 5460 & 0.28 & 0.05 & 1.87 & 7.61 & 1.73 & -1.05 & 1.2 \\
\hline
\end{tabular}

Table 2: W1 and W2 strengthening details.

\begin{tabular}{|c|c|c|c|c|}
\hline \multirow{2}{*}{$\begin{array}{c}\text { Base } \\
\text { Wall }\end{array}$} & $\begin{array}{c}\text { Strengthening } \\
\text { Type }\end{array}$ & $\begin{array}{c}\text { Concrete } \\
\text { thickness }\end{array}$ & \multicolumn{2}{|c|}{ Reinforcement ratio } \\
\cline { 3 - 5 } & & $\begin{array}{c}t_{c} \\
(\mathrm{~mm})\end{array}$ & $\rho_{x}$ & $\rho_{y}$ \\
\hline \multirow{2}{*}{ W1 } & RET1 & 40 & 0.01 & 0.01 \\
\cline { 2 - 5 } & RET2 & 100 & 0.005 & 0.01 \\
\hline \multirow{2}{*}{ W2 } & RET1 & 60 & 0.001 & 0.005 \\
\cline { 2 - 5 } & RET2 & 20 & 0.001 & 0.008 \\
\hline
\end{tabular}

Table 3: Strengthening details adopted for base walls.

\begin{tabular}{|c|c|c|c|c|c|c|}
\hline \multirow{2}{*}{$\begin{array}{l}\text { Base wall } \\
\text { behavior }\end{array}$} & \multirow{2}{*}{$\begin{array}{l}\text { Wall } \\
\text { No. }\end{array}$} & \multirow{2}{*}{$\begin{array}{c}t_{c} \\
(\mathrm{~mm})\end{array}$} & \multicolumn{3}{|c|}{ Reinforcement ratio } & \multirow{2}{*}{$\begin{array}{l}\text { Strengthened wall } \\
\text { behavior }\end{array}$} \\
\hline & & & $\rho_{x}$ & $\rho_{y}$ & $\begin{array}{c}\text { Foundation } \\
\text { joint }\end{array}$ & \\
\hline \multirow{4}{*}{ Bed-joint sliding } & B1 & 40 & 0.003 & 0.003 & 0.003 & Rocking \\
\hline & B2 & 40 & 0.003 & 0.003 & 0.006 & Flexural Cracking \\
\hline & B3 & 40 & 0.003 & 0.001 & 0.003 & Diagonal Tension \\
\hline & B4 & 40 & 0.001 & 0.005 & 0.005 & Diagonal Tension \\
\hline \multirow{3}{*}{ Rocking } & R1 & 40 & 0.003 & 0.003 & 0.003 & Rocking \\
\hline & R2 & 40 & 0.006 & 0.001 & 0.006 & Diagonal Tension \\
\hline & R3 & 40 & 0.003 & 0.001 & 0.003 & Diagonal Tension \\
\hline
\end{tabular}

Table 4: Nonlinear and linear static procedure parameters for strengthened walls.

\begin{tabular}{|c|c|c|c|c|c|c|c|c|c|c|c|c|c|c|c|}
\hline \multirow{3}{*}{ Condition } & \multirow{3}{*}{$f_{a e} / f_{m e}$} & \multirow{3}{*}{$\rho_{g} f_{y e} / f_{m e}$} & \multirow{3}{*}{$d \%$} & \multirow{3}{*}{$e \%$} & \multirow{3}{*}{$c$} & \multicolumn{5}{|c|}{ Acceptance Criteria } & \multicolumn{5}{|c|}{$m$ factors } \\
\hline & & & & & & \multirow{2}{*}{$\begin{array}{l}\text { IO } \\
\% \\
\end{array}$} & \multicolumn{2}{|c|}{ Primary } & \multicolumn{2}{|c|}{ Secondary } & \multirow{2}{*}{$\begin{array}{l}\text { IO } \\
\% \\
\end{array}$} & \multicolumn{2}{|c|}{ Primary } & \multicolumn{2}{|c|}{ Secondary } \\
\hline & & & & & & & LS\% & $\mathrm{CP} \%$ & $\mathrm{LS} \%$ & $\mathrm{CP} \%$ & & $\mathrm{LS} \%$ & $\mathrm{CP} \%$ & $\mathrm{LS} \%$ & $\mathrm{CP} \%$ \\
\hline \multirow{4}{*}{ Flexure } & \multirow{2}{*}{$\leq 0.04$} & $\leq 0.07$ & 1 & 1.5 & 0.7 & 0.3 & 0.75 & 1 & 1.1 & 1.5 & 4 & 7 & 8 & 8 & 10 \\
\hline & & $\geq 0.07$ & 0.5 & 1 & 0.7 & $\overline{0.1}$ & 0.37 & 0.5 & 0.75 & 1 & 1.5 & 2 & 2.5 & 4 & 5 \\
\hline & \multirow{2}{*}{$\geq 0.04$} & $\leq 0.07$ & 0.6 & 1 & $\overline{0.5}$ & $\overline{0.2}$ & 0.45 & 0.6 & 0.75 & 1 & 2 & 3.5 & 4.5 & 7 & 9 \\
\hline & & $\geq 0.07$ & 0.4 & 0.8 & 0.5 & 0.1 & 0.3 & 0.4 & 0.6 & 0.8 & 1 & 2 & 2.5 & 4 & 5 \\
\hline \multicolumn{3}{|c|}{ Shear (diagonal tension) } & 0.75 & 1.2 & 0.4 & $\overline{0.4}$ & 0.6 & 0.75 & 0.75 & 1.2 & 2 & 2 & 3 & 2 & 3 \\
\hline \multicolumn{3}{|c|}{ Shear sliding } & 0.4 & 0.8 & 0.6 & $\overline{0.1}$ & 0.3 & 0.4 & 0.6 & 0.8 & 1 & 3 & 4 & 6 & 8 \\
\hline
\end{tabular}


Table 5: Yaghoubifar (2008) strengthened specimens.

\begin{tabular}{|c|c|c|c|c|c|c|c|c|c|c|c|c|c|c|c|}
\hline \multirow{3}{*}{ Wall } & \multirow{2}{*}{\multicolumn{5}{|c|}{ Masonry wall characteristics }} & \multicolumn{10}{|c|}{ Strengthening detail } \\
\hline & & & & & & \multicolumn{2}{|c|}{ Concrete } & \multicolumn{4}{|c|}{ Vertical Reinforcement } & \multicolumn{4}{|c|}{ Horizontal Reinforcement } \\
\hline & $\begin{array}{c}l_{w} \\
(\mathrm{~mm})\end{array}$ & $\begin{array}{c}h_{w} \\
(\mathrm{~mm})\end{array}$ & $\begin{array}{c}t_{m} \\
(\mathrm{~mm})\end{array}$ & $\begin{array}{c}f^{\prime}{ }_{m} \\
(\mathrm{MPa})\end{array}$ & $\begin{array}{c}P \\
(\mathrm{KN})\end{array}$ & $\begin{array}{c}t_{c} \\
(\mathrm{~mm})\end{array}$ & $\begin{array}{c}f_{c}^{\prime} \\
(\mathrm{MPa})\end{array}$ & $\rho_{y}$ & $\begin{array}{c}d \\
(\mathrm{~mm})\end{array}$ & $\begin{array}{r}\text { Dist. } \\
(\mathrm{mm})\end{array}$ & $\begin{array}{c}f_{y} \\
(\mathrm{MPa})\end{array}$ & $\rho$ & $\begin{array}{c}d \\
(\mathrm{~mm})\end{array}$ & $\begin{array}{l}\text { Dist. } \\
(\mathrm{mm})\end{array}$ & $\begin{array}{c}f_{y} \\
(\mathrm{MPa})\end{array}$ \\
\hline SSBW2 & 1800 & 800 & 200 & 5 & 60 & 40 & 28 & 0.0063 & 4 & 50 & 309.6 & 0.0063 & 4 & 50 & 309.6 \\
\hline DSBW2 & 1800 & 800 & 200 & 5 & 60 & 40 & 28 & 0.0063 & 4 & 50 & 309.6 & 0.0063 & 4 & 50 & 309.6 \\
\hline SSBW1 & 1800 & 1200 & 200 & 5 & 40 & 40 & 28 & 0.0028 & 4 & 100 & 650 & 0.003 & 4 & 100 & 650 \\
\hline DSBW1 & 1800 & 1200 & 200 & 5 & 40 & 40 & 28 & 0.0028 & 4 & 100 & 650 & 0.003 & 4 & 100 & 650 \\
\hline
\end{tabular}

Table 6: Capacity prediction of Yaghoubifar (2008) strengthened specimens.

\begin{tabular}{|c|c|c|c|c|c|c|c|}
\hline \multirow{2}{*}{ Wall } & \multirow{2}{*}{$\begin{array}{c}\text { Sliding } \\
\text { strength } \\
V_{s e} \\
(\mathrm{KN})\end{array}$} & \multirow{2}{*}{$\begin{array}{c}\text { Shear } \\
\text { strength } \\
V_{s r m} \\
(\mathrm{KN})\end{array}$} & \multirow{2}{*}{$\begin{array}{c}\text { Flexural } \\
\text { strength } \\
V_{f} \\
(\mathrm{KN})\end{array}$} & \multirow{2}{*}{$\begin{array}{c}\text { Total } \\
\text { strength } \\
(\mathrm{KN})\end{array}$} & \multirow{2}{*}{$\begin{array}{c}\text { Exp. } \\
\text { Strength } \\
(\mathrm{KN})\end{array}$} & \multicolumn{2}{|c|}{ Failure Mode } \\
\hline & & & & & & Experiment & Predicted \\
\hline SSBW2 & 168 & 139 & 216 & 139 & 135 & Diagonal Tension & Diagonal Tension \\
\hline DSBW2 & 295 & 444 & 259 & 259 & 270 & Flexural & Flexural \\
\hline SSBW1 & 146 & 152 & 43 & 43 & 42 & Flexural & Flexural \\
\hline DSBW1 & 264 & 449 & 48 & 48 & 50 & Flexural & Flexural \\
\hline
\end{tabular}

Table 7: Strengthening details in S2-1SHOT-ST wall.

\begin{tabular}{|c|c|c|c|c|c|c|c|c|c|c|c|c|c|c|}
\hline \multirow{3}{*}{ Wall } & \multirow{2}{*}{\multicolumn{5}{|c|}{ Masonry wall characteristics }} & \multicolumn{9}{|c|}{ Strengthening detail } \\
\hline & & & & & & \multirow{2}{*}{\begin{tabular}{|c|} 
Concrete \\
$t_{c}$ \\
$(\mathrm{~mm})$ \\
\end{tabular}} & \multicolumn{4}{|c|}{ Vertical Reinforcement } & \multicolumn{4}{|c|}{ Horizontal Reinforcement } \\
\hline & $\begin{array}{c}l_{w} \\
(\mathrm{~mm})\end{array}$ & $\begin{array}{c}h_{w} \\
(\mathrm{~mm})\end{array}$ & $\begin{array}{c}t_{m} \\
(\mathrm{~mm})\end{array}$ & $\begin{array}{c}f^{\prime}{ }_{m} \\
(\mathrm{MPa})\end{array}$ & $\begin{array}{c}P \\
(\mathrm{KN})\end{array}$ & & $\rho_{y}$ & $\begin{array}{c}d \\
(\mathrm{~mm})\end{array}$ & $\begin{array}{l}\text { Dist. } \\
(\mathrm{mm})\end{array}$ & $\begin{array}{c}f_{y} \\
(\mathrm{MPa})\end{array}$ & $\rho_{x}$ & $\begin{array}{c}d \\
(\mathrm{~mm})\end{array}$ & $\begin{array}{c}\text { Dist. } \\
(\mathrm{mm})\end{array}$ & $\begin{array}{c}f_{y} \\
(\mathrm{MPa})\end{array}$ \\
\hline S2-1SHOT-ST & 1600 & 730 & 75 & 4.8 & 39 & 20 & 0.006 & 4 & 100 & 745 & 0.006 & 4 & 100 & 745 \\
\hline $4 \mathrm{~F}$ & 843 & 1490 & 200 & 7.86 & 23 & 100 & 0.002 & 9.5 & 700 & 420 & 0.004 & 9.5 & 220 & 420 \\
\hline
\end{tabular}

Table 8: Strengthening details adopted for wall W1.

\begin{tabular}{|c|c|c|c|c|c|c|c|c|c|c|c|c|c|c|c|}
\hline \multirow{3}{*}{ Wall } & \multirow{2}{*}{\multicolumn{5}{|c|}{ Masonry wall characteristics }} & \multicolumn{10}{|c|}{ Strengthening detail } \\
\hline & & & & & & \multicolumn{2}{|c|}{ Concrete } & \multicolumn{4}{|c|}{ Vertical Reinforcement } & \multicolumn{4}{|c|}{ Horizontal Reinforcement } \\
\hline & $\begin{array}{c}l_{w} \\
(\mathrm{~mm})\end{array}$ & $\begin{array}{c}h_{w} \\
(\mathrm{~mm})\end{array}$ & $\begin{array}{c}t_{m} \\
(\mathrm{~mm})\end{array}$ & $\begin{array}{c}f_{m}^{\prime}{ }_{m} \\
(\mathrm{MPa})\end{array}$ & $\begin{array}{c}P \\
(\mathrm{KN}) \\
\end{array}$ & $\begin{array}{c}t_{c} \\
(\mathrm{~mm})\end{array}$ & $\begin{array}{c}f_{c}^{\prime} \\
(\mathrm{MPa})\end{array}$ & $\rho_{y}$ & $\begin{array}{c}d \\
(\mathrm{~mm})\end{array}$ & $\begin{array}{l}\text { Dist. } \\
(\mathrm{mm})\end{array}$ & $\begin{array}{c}f_{y} \\
(\mathrm{MPa})\end{array}$ & $\rho_{x}$ & $\begin{array}{c}d \\
(\mathrm{~mm})\end{array}$ & $\begin{array}{l}\text { Dist. } \\
(\mathrm{mm})\end{array}$ & $\begin{array}{c}f_{y} \\
(\mathrm{MPa})\end{array}$ \\
\hline W1-1 & 3600 & 2000 & 150 & 7.61 & 423.03 & 40 & 30 & 0.01 & 8 & 125 & 400 & 0.01 & 8 & 125 & 400 \\
\hline W1-3 & 3600 & 2000 & 150 & 7.61 & 423.03 & 40 & 30 & 0.008 & 8 & 160 & 400 & 0.003 & 8 & 420 & 400 \\
\hline W1-6 & 3600 & 2000 & 150 & 7.61 & 423.03 & 100 & 30 & 0.01 & 10 & 60 & 400 & 0.005 & 10 & 120 & 400 \\
\hline
\end{tabular}

Table 9: Comparison of analysis and proposed relations.

\begin{tabular}{|c|c|c|c|c|}
\hline \multirow{2}{*}{ Wall } & \multicolumn{2}{|c|}{ Analysis results } & \multicolumn{2}{c|}{ Proposed relations } \\
\cline { 2 - 5 } & $\begin{array}{c}\text { Strength } \\
(\mathrm{KN})\end{array}$ & Failure mode & $\begin{array}{c}\text { Strength } \\
(\mathrm{KN})\end{array}$ & Failure mode \\
\hline W1-1 & 69 & Flexural & 60.2 & Flexural \\
\hline W1-3 & 60 & Flexural & 54 & Flexural \\
\hline W1-6 & 120 & Diagonal Tension & 104.5 & Diagonal Tension \\
\hline
\end{tabular}




\section{Figures}

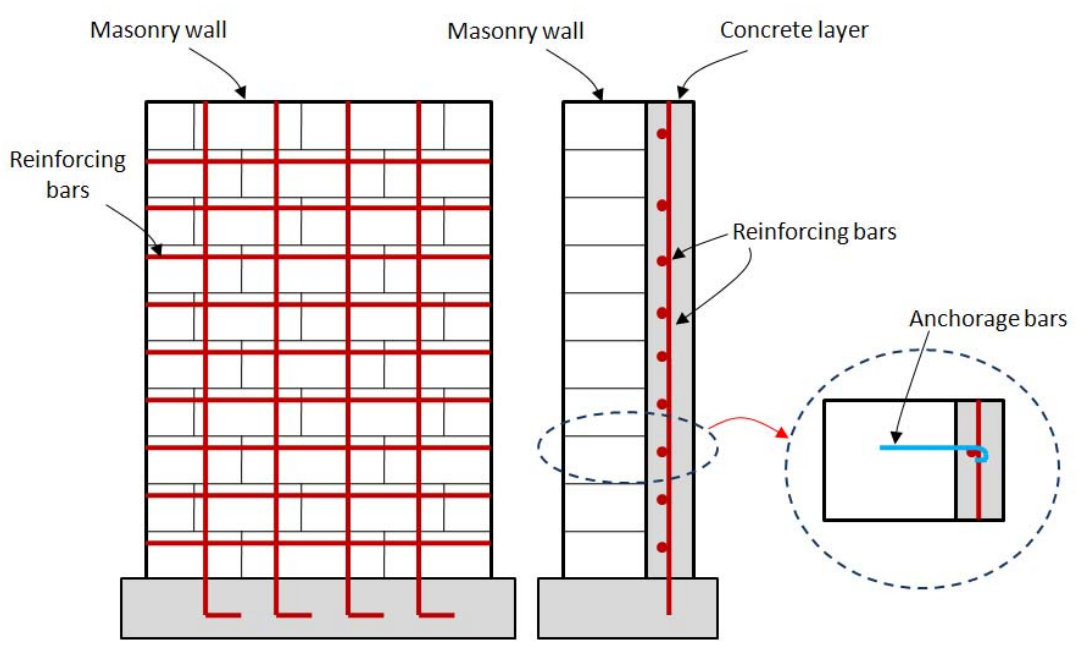

Figure 1: Typical detail of masonry wall strengthening with reinforced concrete layer.

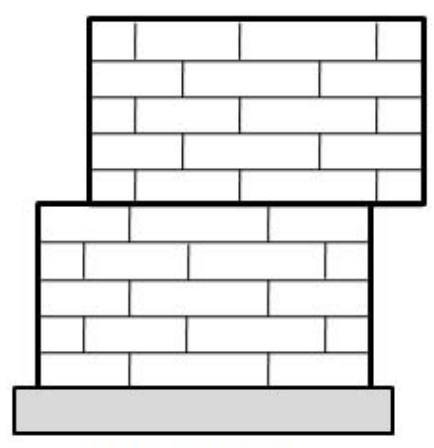

Bed-joint sliding

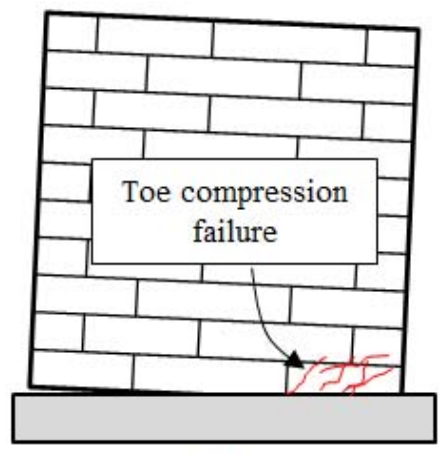

Rocking

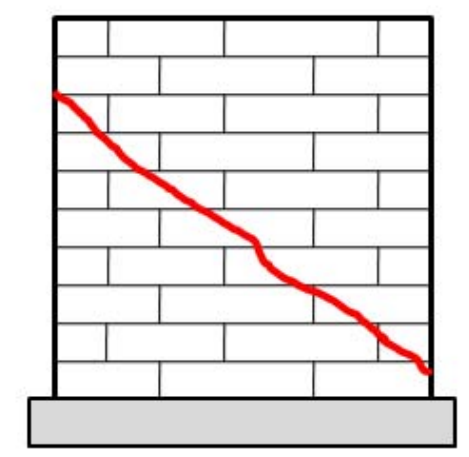

Diagonal cracking

Figure 2: Failure modes in unreinforced masonry walls.

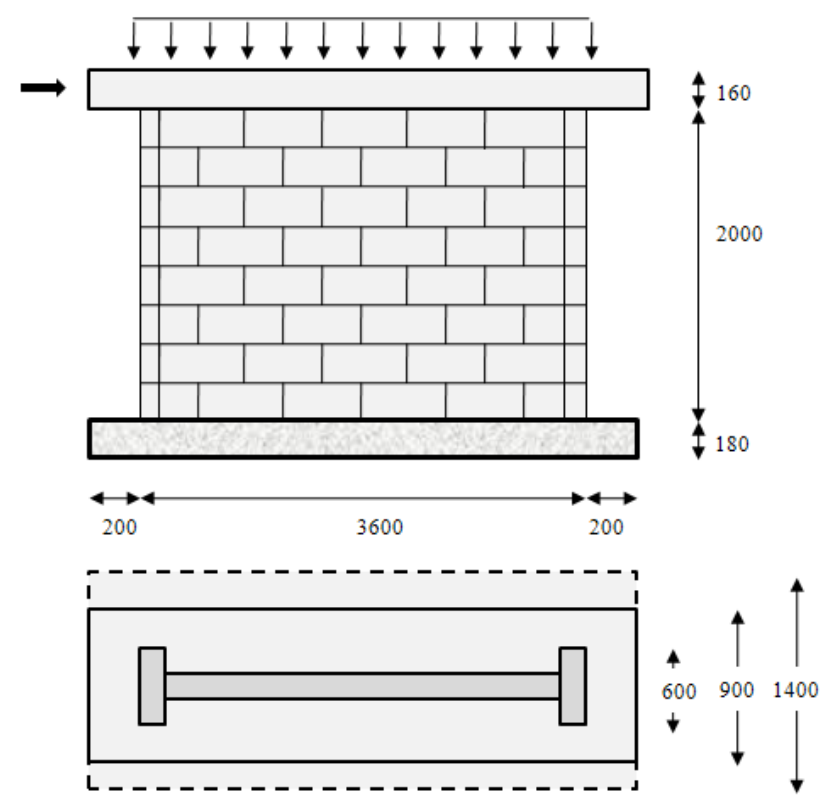

Figure 3: Geometry of the ETH Zurich walls. 


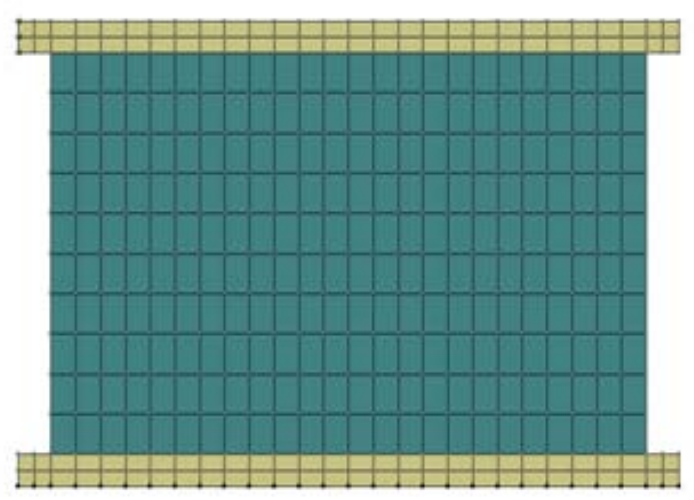

Figure 4: The generated mesh for macro modeling of the ETH Zurich walls.
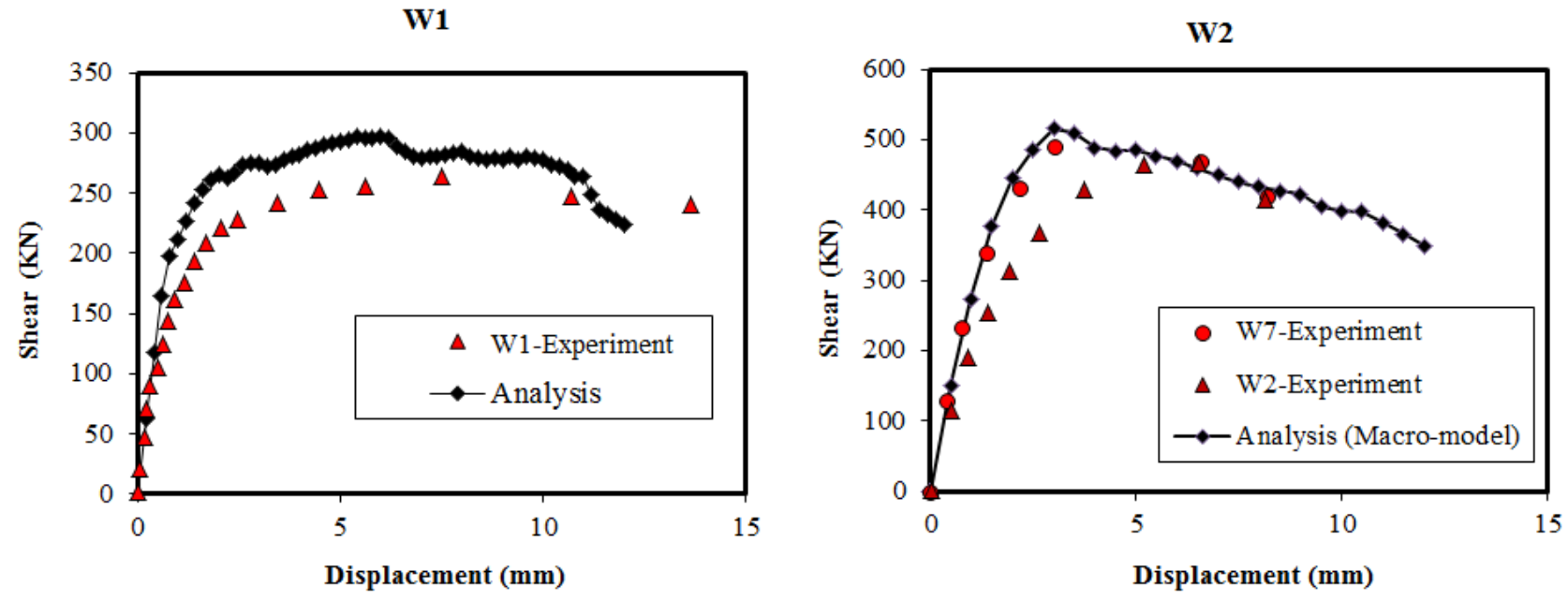

Figure 5: Analysis results for walls W1 and W2.
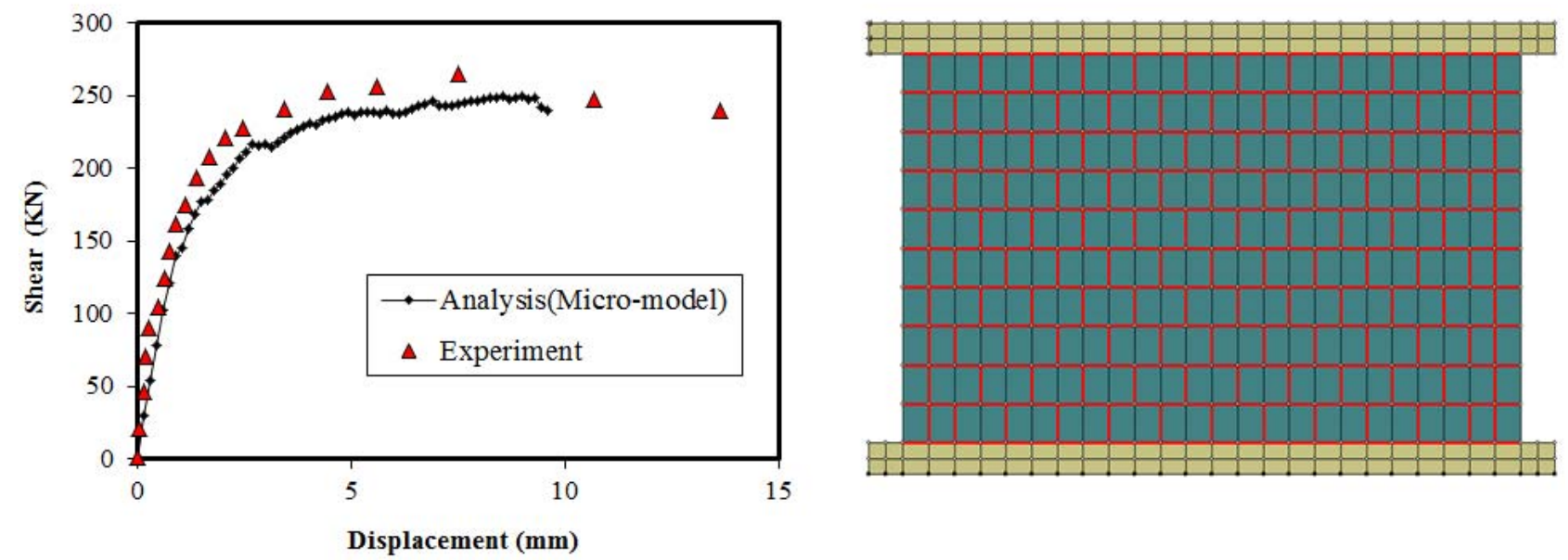

Figure 6: Micro modeling results for wall W1. 

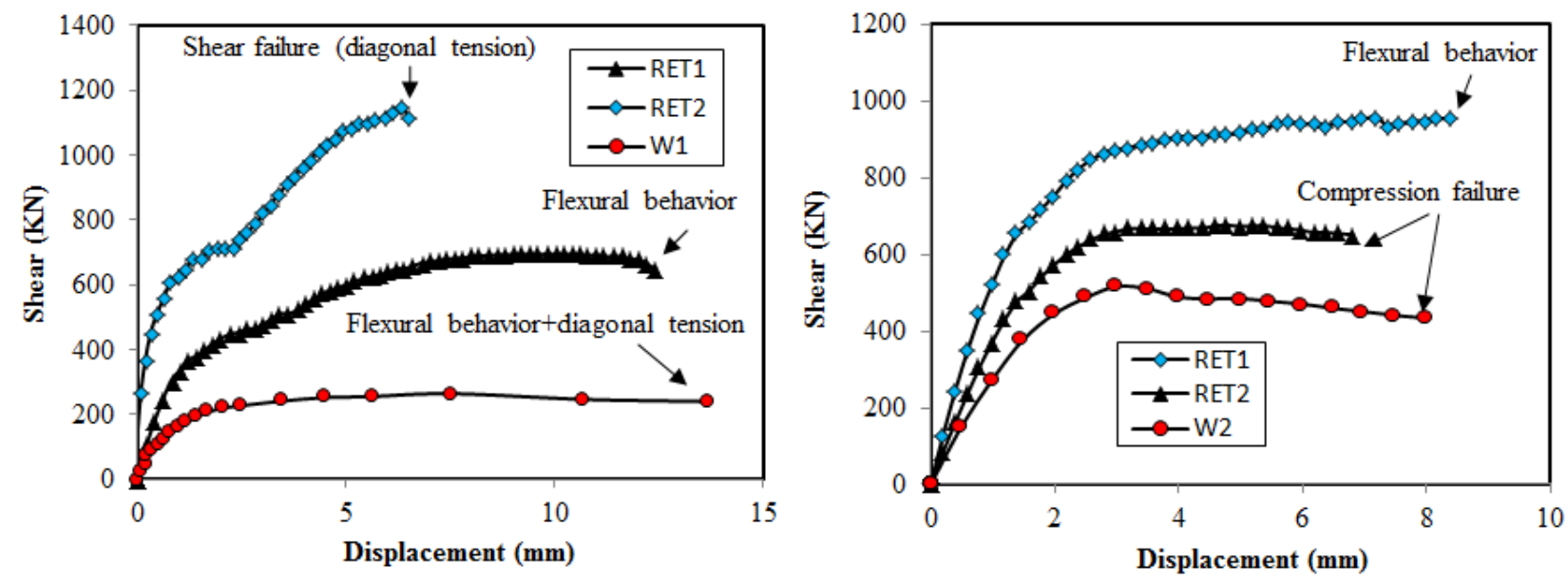

Figure 7: W1 and W2 strengthened walls behavior.

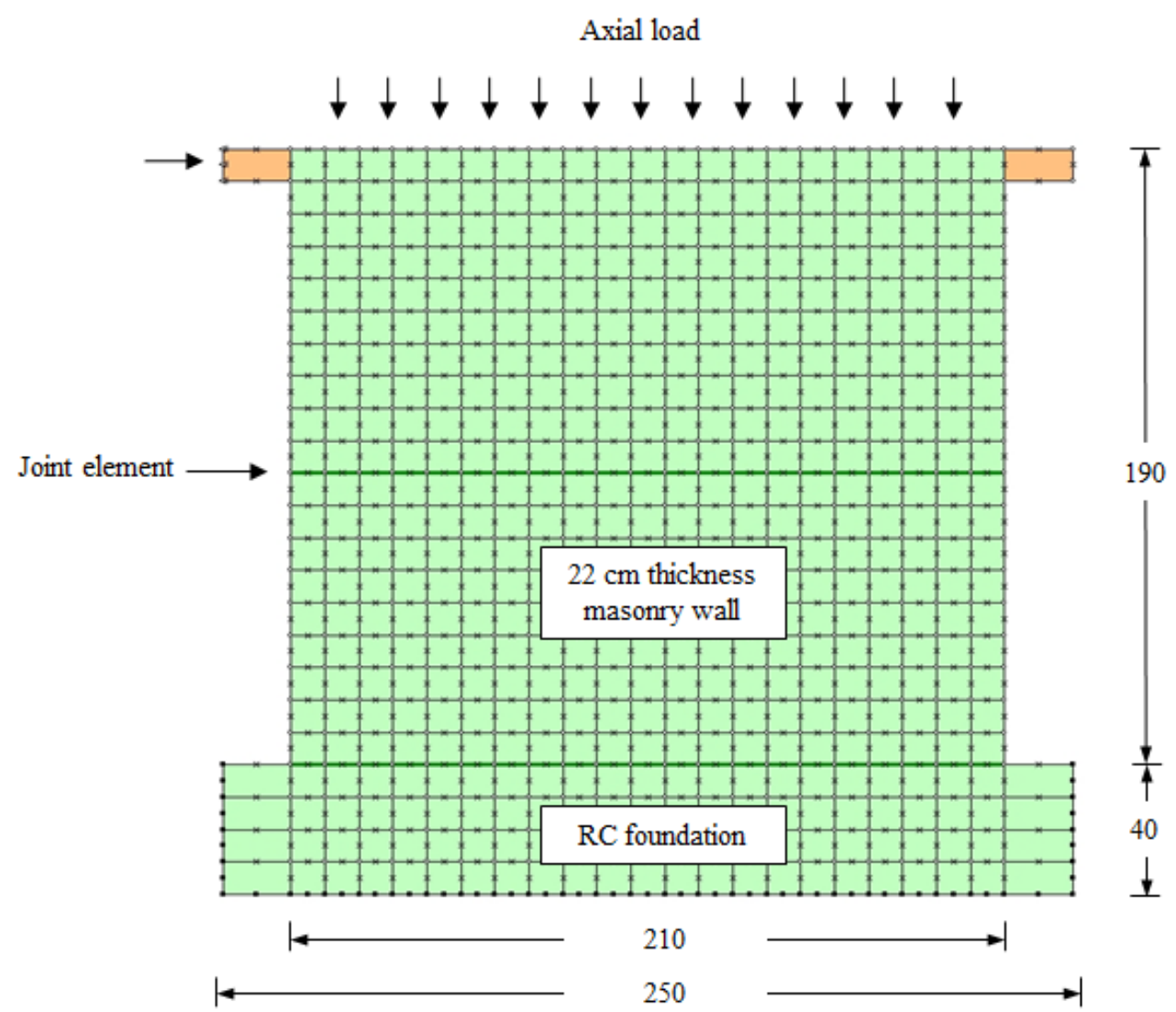

Figure 8: Finite element model of masonry wall with bed-joint sliding behavior. 

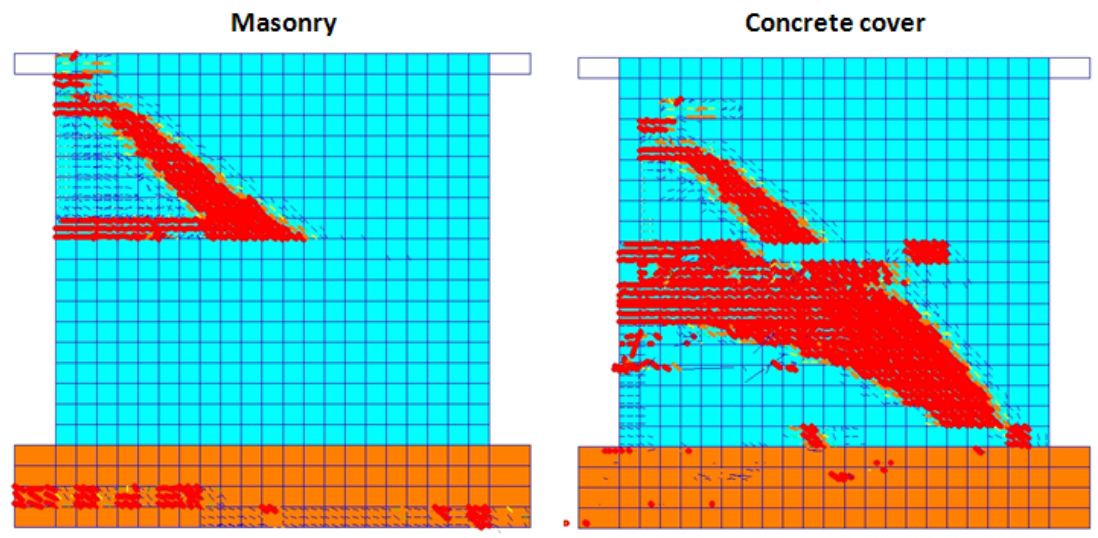

Figure 9: Crack distribution in wall B3.

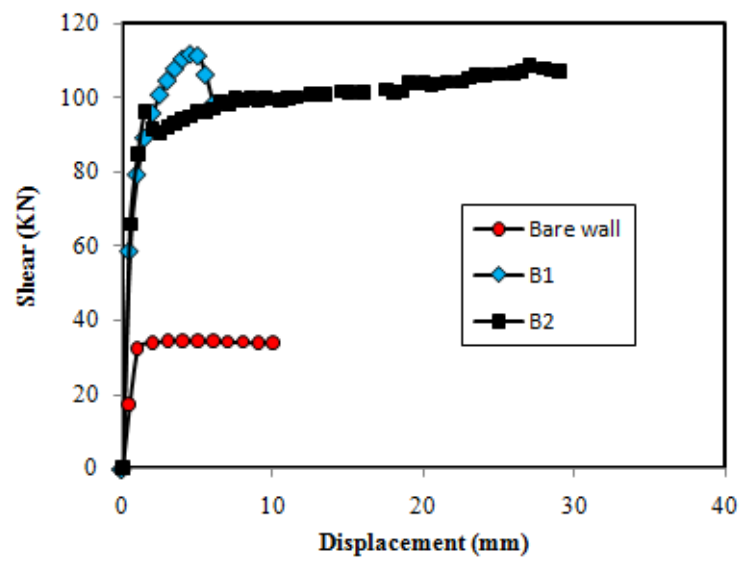

Figure 10: Shear displacement curve of the strengthened walls with initial bed-joint-sliding behavior.

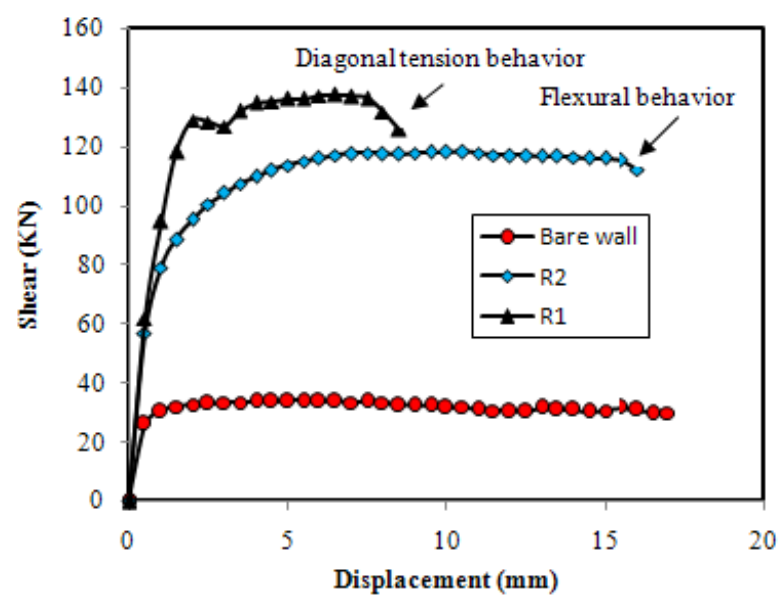

Figure 11: Shear displacement curve of the strengthened walls with initial rocking behavior. 


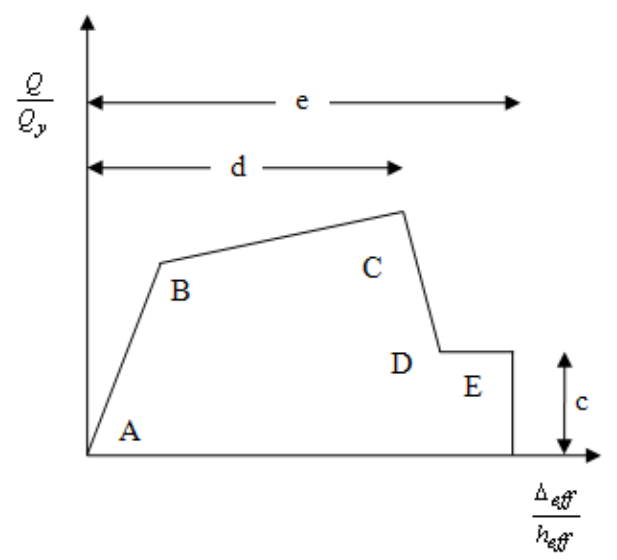

Figure 12: General force-deformation curve.

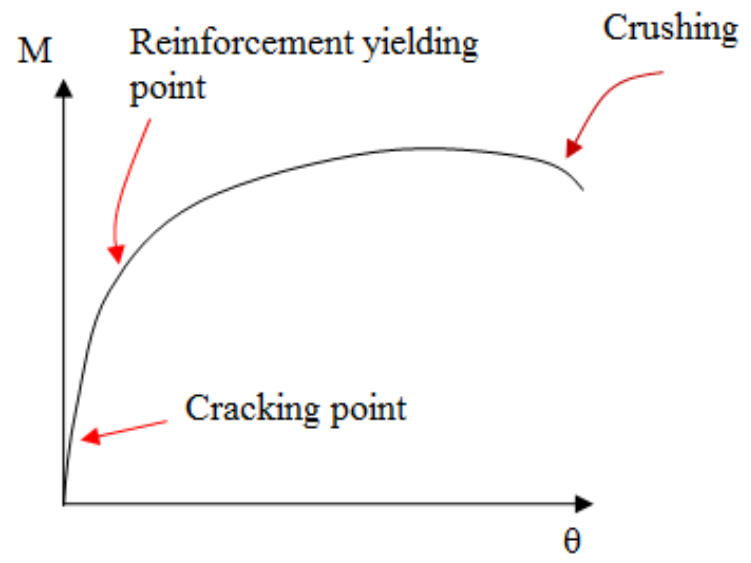

Figure 13: Moment curvature behavior of a strengthened masonry wall.
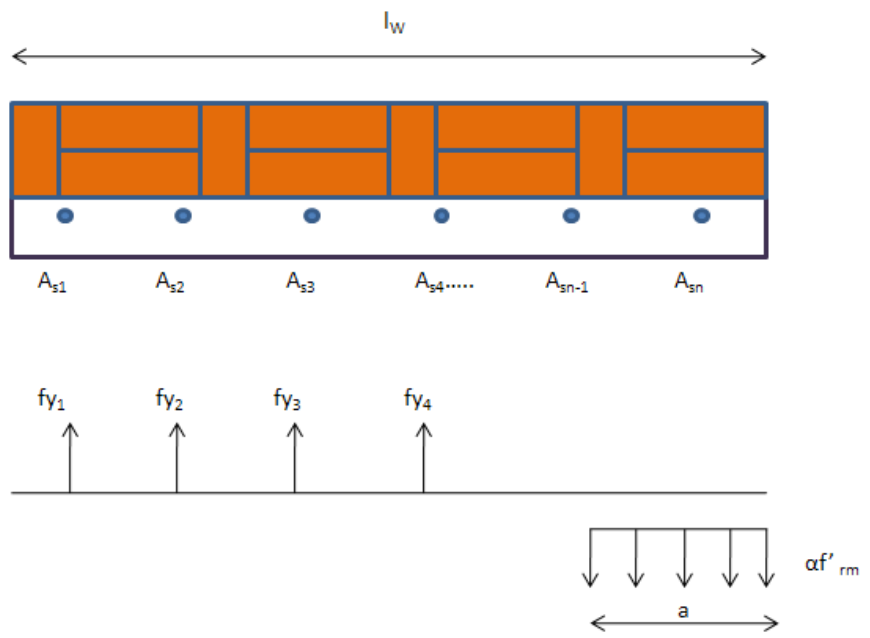

Figure 14: The wall section and assumed stress distribution. 


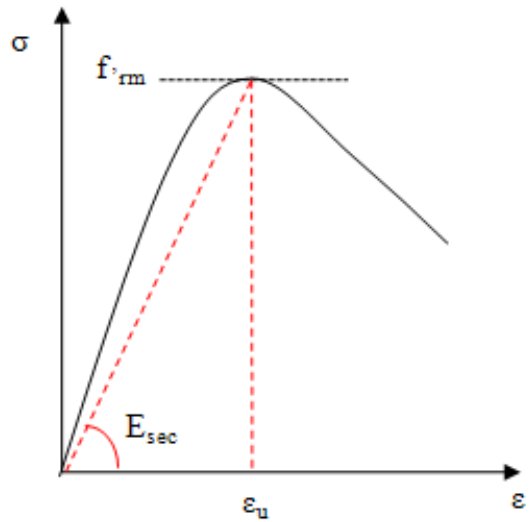

Figure 15: Equivalent compressive strength.
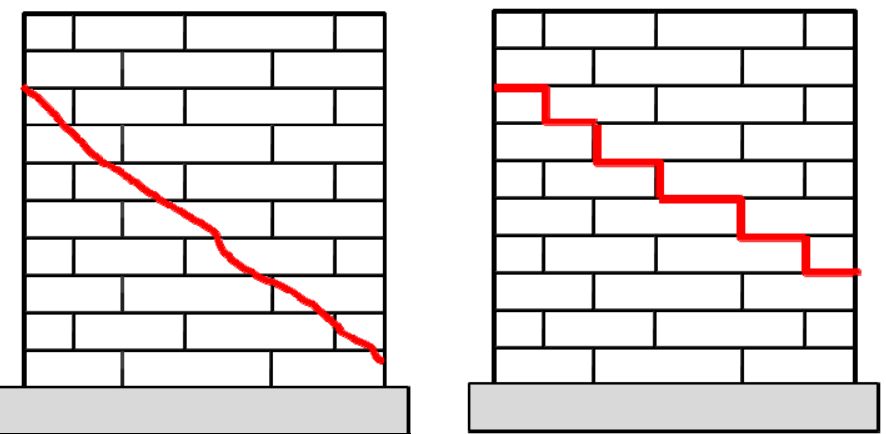

Figure 16: Crack distribution in unreinforced masonry.

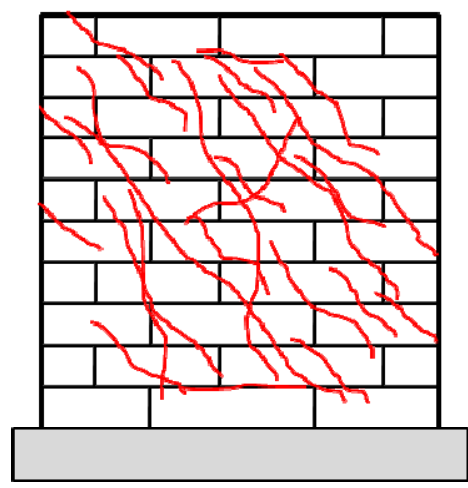

Figure 17: Crack distribution in reinforced masonry.

Minimum required reinforcement ratio

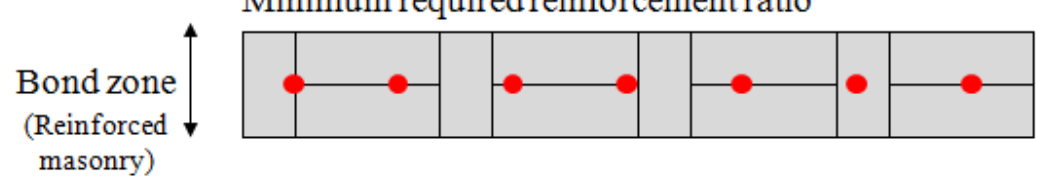

Low reinforcement ratio

Bond zone (Reinforced masonry)
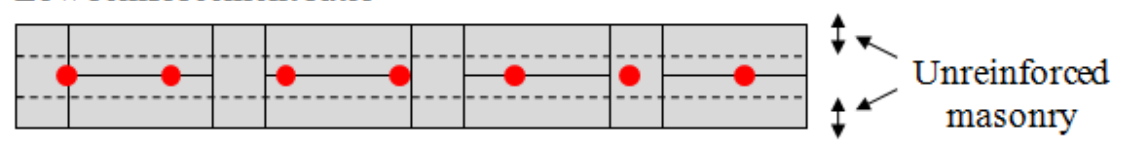

Figure 18: Bond zone in reinforced masonry. 


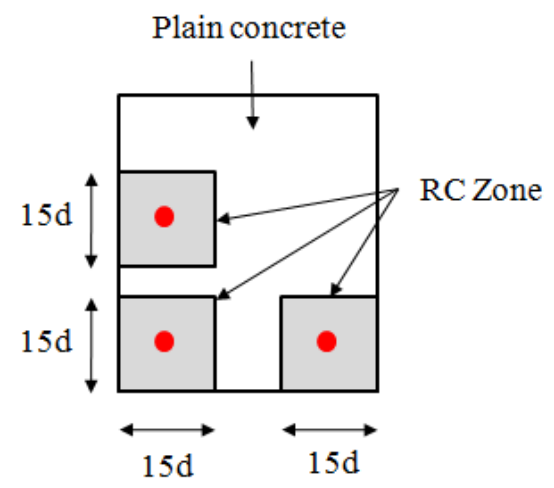

Figure 19: Definition of RC zone.

Total gravity load $=60 \mathrm{KN}$
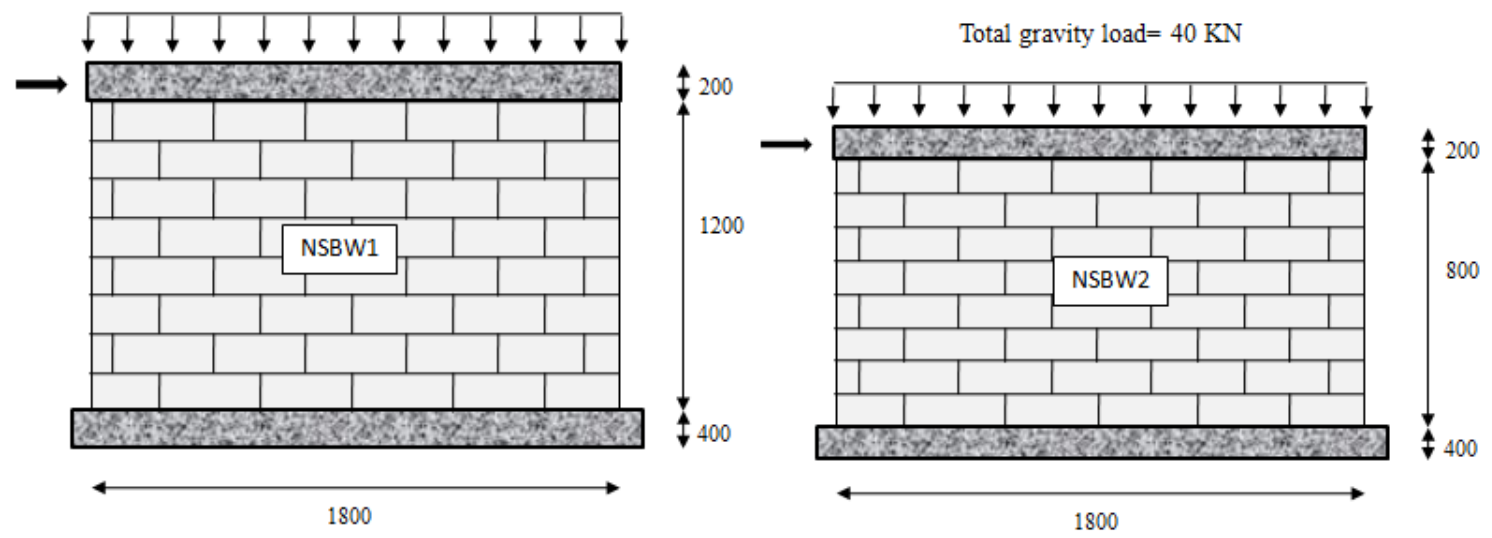

Figure 20: Basic unreinforced masonry specimens tested by Yaghoubifar (2008).
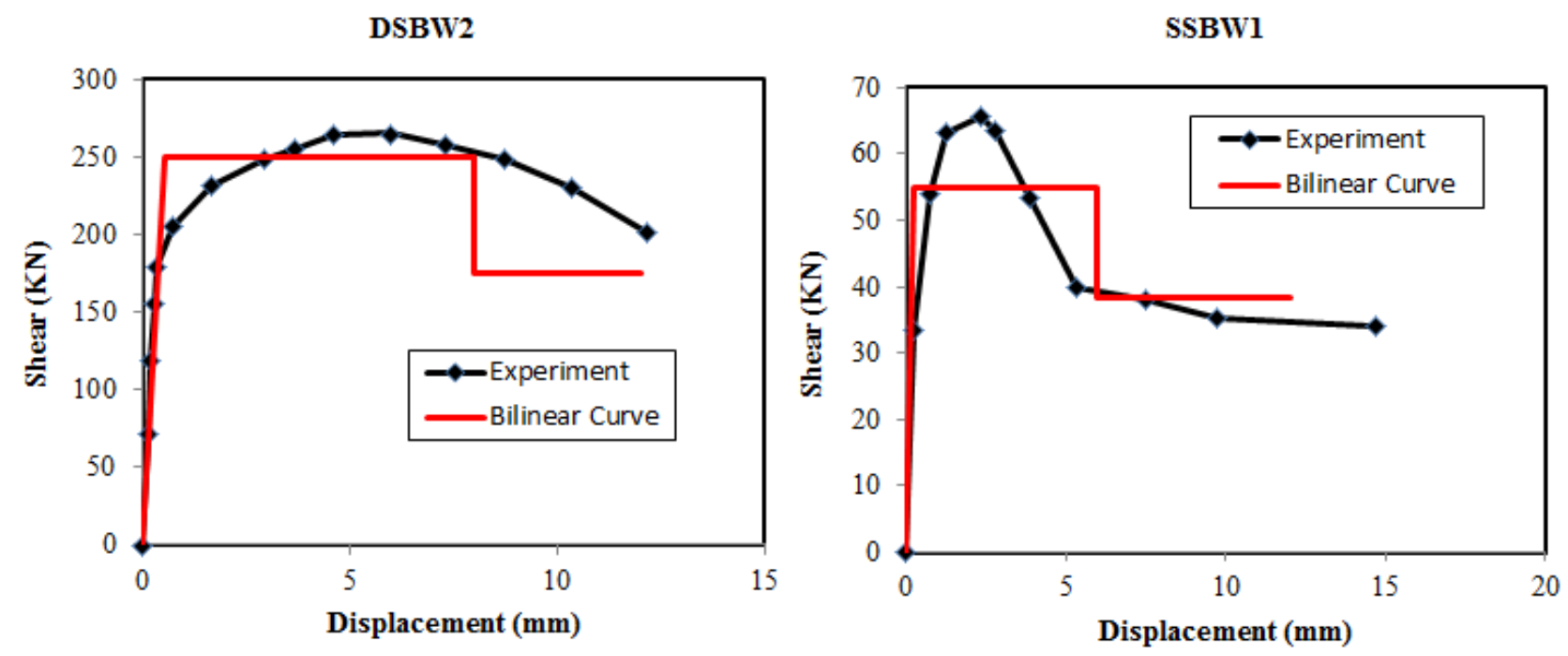

Figure 21: SSBW1 and DSBW2 bilinear curves. 

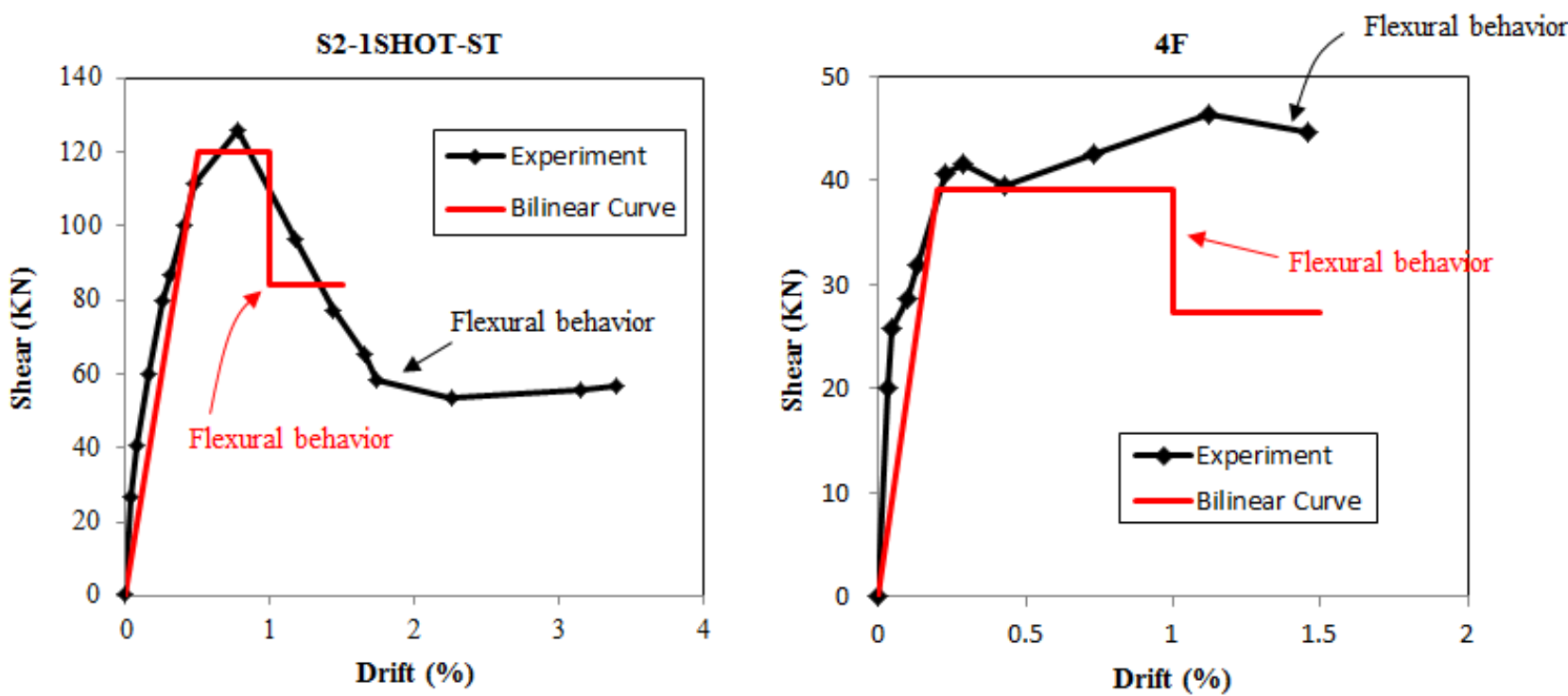

Figure 22: Comparison of experimental result with proposed bilinear curves.
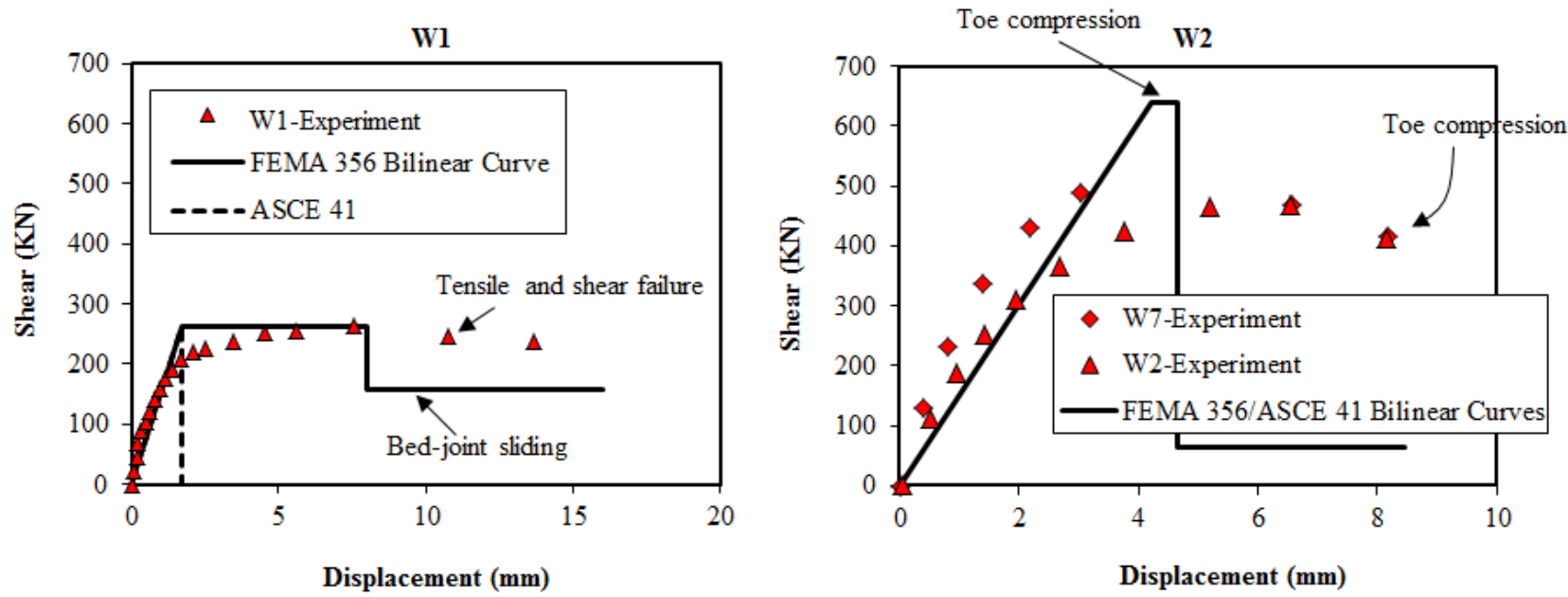

Figure 23: Behavior of wall W1 and W2.
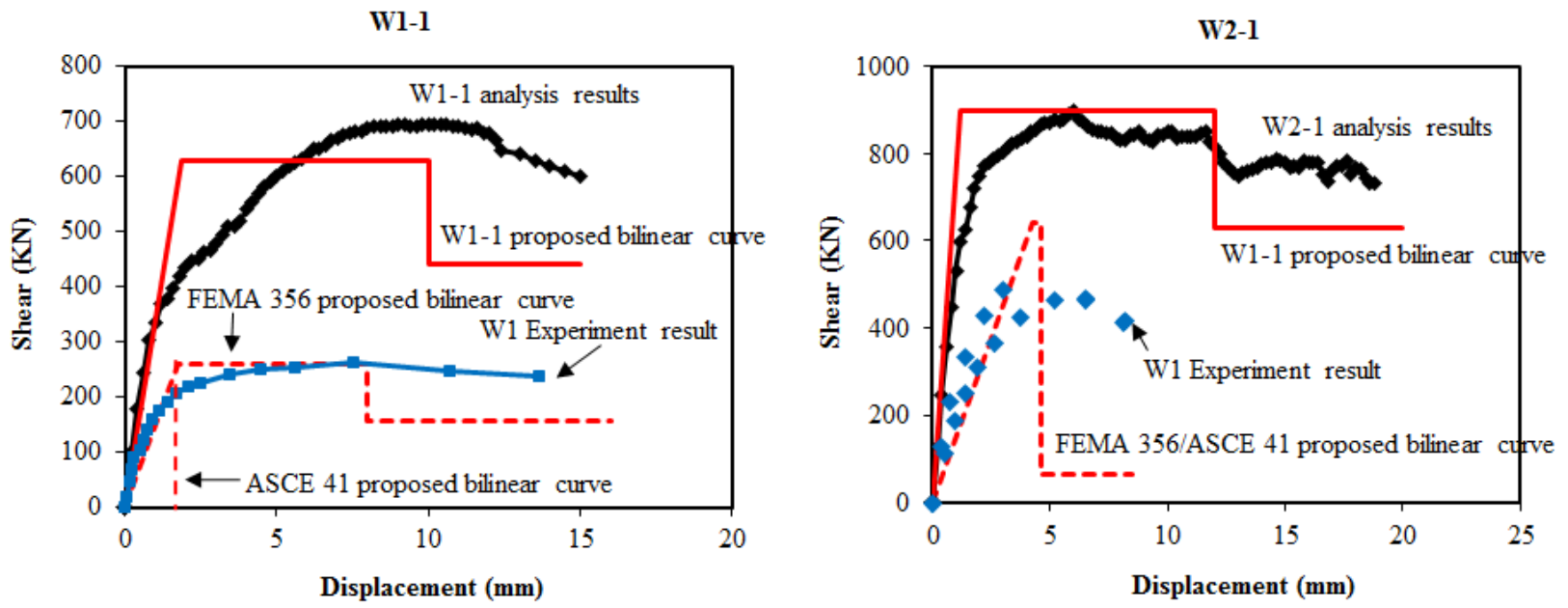

Figure 24: Bilinear curves of the strengthened walls. 